\title{
Hippocampal temporal-parietal junction interaction in the production of psychotic symptoms: a framework for understanding the schizophrenic syndrome
}

\author{
Cynthia G. Wible* \\ Laboratory for Neuroscience, Department of Psychiatry, Harvard Medical School, Brockton, MA, USA
}

\section{Edited by:}

Hauke R. Heekeren, Freie

Universität Berlin, Germany

Reviewed by:

Shozo Tobimatsu, Kyushu

University, Japan

Karin Laimboeck, University Hospital

of Psychiatry, Switzerland

Georg Winterer, University of

Colgone, Germany

${ }^{*}$ Correspondence:

Cynthia G. Wible, Laboratory for Neuroscience, Department of

Psychiatry, Harvard Medical School, Psychiatry 116A, VA Boston

Healthcare System, 940 Belmont

Street, Brockton, MA 02301, USA

e-mail: cindy@bwh.harvard.edu
A framework is described for understanding the schizophrenic syndrome at the brain systems level. It is hypothesized that over-activation of dynamic gesture and social perceptual processes in the temporal-parietal occipital junction (TPJ), posterior superior temporal sulcus (PSTS) and surrounding regions produce the syndrome (including positive and negative symptoms, their prevalence, prodromal signs, and cognitive deficits). Hippocampal system hyper-activity and atrophy have been consistently found in schizophrenia. Hippocampal activity is highly correlated with activity in the TPJ and may be a source of over-excitation of the TPJ and surrounding regions. Strong evidence for this comes from in-vivo recordings in humans during psychotic episodes. Many positive symptoms of schizophrenia can be reframed as the erroneous sense of a presence or other who is observing, acting, speaking, or controlling; these qualia are similar to those evoked during abnormal activation of the TPJ. The TPJ and PSTS play a key role in the perception (and production) of dynamic social, emotional, and attentional gestures for the self and others (e.g., body/face/eye gestures, audiovisual speech and prosody, and social attentional gestures such as eye gaze). The single cell representation of dynamic gestures is multimodal (auditory, visual, tactile), matching the predominant hallucinatory categories in schizophrenia. Inherent in the single cell perceptual signal of dynamic gesture representations is a computation of intention, agency, and anticipation or expectancy (for the self and others). Stimulation of the TPJ resulting in activation of the self representation has been shown to result a feeling of a presence or multiple presences (due to heautoscopy) and also bizarre tactile experiences. Neurons in the TPJ are also tuned, or biased to detect threat related emotions. Abnormal over-activation in this system could produce the conscious hallucination of a voice (audiovisual speech), a person or a touch. Over-activation could interfere with attentional/emotional gesture perception and production (negative symptoms). It could produce the unconscious feeling of being watched, followed, or of a social situation unfolding along with accompanying abnormal perception of intent and agency (delusions). Abnormal activity in the TPJ would also be predicted to create several cognitive disturbances that are characteristic of schizophrenia, including abnormalities in attention, predictive social processing, working memory, and a bias to erroneously perceive threat.

Keywords: hippocampus, schizophrenia, parietal, biological motion, superior temporal sulcus, intraparietal sulcus, autism, social cognition

\section{OVERVIEW}

A framework will be presented to account for the positive symptoms (hallucinations, delusions) negative symptoms (e.g., affective unresponsiveness), prodromal signs, and cognitive deficits of schizophrenia. It is posited that the phenomenological aspects of the syndrome stem from the over-activation of the same or adjacent neural elements within the temporal-parietal occipital junction (TPJ), the posterior superior temporal sulcus (PSTS) and surrounding cortical regions. Activity in the TPJ is coupled with hippocampal activity, a region that has been consistently implicated in schizophrenia. Hence over-activation may stem from abnormal activity in the hippocampal formation, an area that is prone to excitotoxic activity. Abnormal activity in these regions would also lead to abnormal activity in efferent frontal lobe regions (these regions are shown in the figures throughout the paper). The framework accounts for several recent findings; volume reductions in schizophrenia have been most frequently found in the hippocampus and the posterior superior (and lateral) temporal regions, including recent single site and multisite studies using large numbers of subjects (Seidman et al., 2003; Honea et al., 2005, 2008; Segall et al., 2009). Over-activation has been found in these regions in schizophrenia and this abnormal activation has been shown to be related to symptoms and cognitive deficits (e.g., Lennox et al., 1999; Han et al., 2007; 
Wible et al., 2009a; Hashimoto et al., 2010). I claim that the pattern or relative prevalence of the symptoms and cognitive deficits are a result of the representational structure at the single cell level and the neural architecture (the adjacency and overlap of function) within the TPJ and particularly the PSTS. Note that the PSTS functional region spans a large area and may extend into superior temporal gyrus as well as into middle and inferior temporal gyri. Regions designated in the literature as TPJ or PSTS often refer to overlapping areas, and the extent of these regions varies between investigations; for this reason, these terms are used loosely to refer to this general region. Evidence from human brain stimulation (both intracranial stimulation and TMS), lesion studies, single unit, and functional imaging studies in monkeys and humans show that these regions act as a coordinated system and may form part of a core neural substrate for dynamic social perception and interaction as well as self representation (e.g., Seltzer and Pandya, 1978, 1994; Lewis and van Essen, 2000; Padberg et al., 2003; Decety and Grezes, 2006; Decety and Lamm, 2007; Hein and Knight, 2008; Redcay, 2008; Wible et al., 2009b; Redcay et al., 2010). In fact a recent study confirmed that TPJ activity was uniquely active during naturalistic live interaction with another person (and joint social attention) when compared to control conditions-see Figure 1 from Redcay et al. (2010). Recently published information from several subfields of cognitive neuroscience is used to reframe the symptoms and qualia that comprise schizophrenia. The functional descriptions of TPJ/PSTS neural systems are laid out in separate sections of the manuscript, but the separation is somewhat arbitrary and used for simplification as the functionality is extensively overlapping. In each section, symptoms and cognitive deficits are described that are proposed to be maximally related to the functions described in those paragraphs.

\section{THE PHENOMENOLOGY OF SCHIZOPHRENIA}

First the phenomenological aspects of the schizophrenic syndrome will briefly described in order to establish what the framework is attempting to explain; some of this information is from a large neuroimaging and clinical dataset from the Functional Biomedical Informatics Network Consortium (Wible

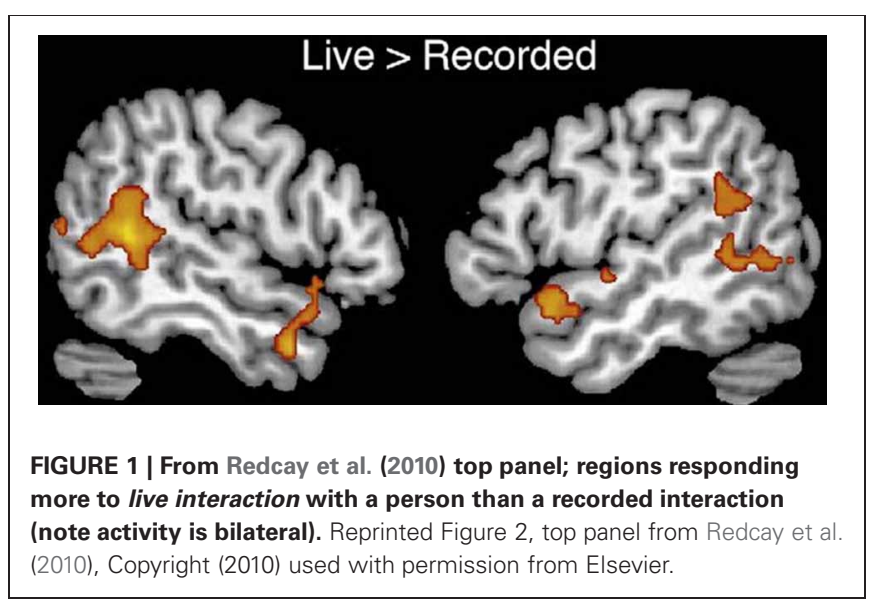

et al., 2009a; Wible and Molina, in preparation). Schizophrenia is characterized by hallucinations and delusions, as well as deficits in attention and working memory. Social cognition is also affected, as well as affective responsiveness. Individuals can present with asociality, a paucity or lack of facial movement, eye contact, vocal inflection, and facial expression. Anhedonia and apathy are sometimes present; impersistence at work and school is also a frequent sign. However, there is evidence that the experience of emotion is not as affected as emotional responsiveness (Kring et al., 1993; Myin-Germeys et al., 2000; Kring and Moran, 2008). Auditory hallucinations of voices are common; approximately $74 \%$ of patients hear voices (Silbersweig and Stern, 1996) and also feel that someone is speaking to them or that there are people talking and present who cannot be seen. Visual hallucinations are present in approximately $56 \%$ of patients and are most often in the form of human figures showing movement (70\%; Gauntlett-Gilbert and Kuipers, 2003). Somatic hallucinations constitute the next largest category of hallucinations and can consist of burning or tingling feelings as well as a perception that the body has changed in shape or size. Somatic delusions also occur and may consist of a perception that the body or face is changed or unusual in some way. A small percentage of patients have olfactory hallucinations. Persecutory delusions often involve the belief that one is being followed, spied upon or harassed by others; some individuals experience delusions of jealousy. This feeling of the presence of another may also be manifested in delusions of reference. Individuals with delusions of reference can feel that others are communicating with them via gestures or secretly observing them (Startup and Startup, 2005). Delusions of control are experienced as a belief that one's feelings or actions are controlled by someone else. This misattribution of agency can also occur for thoughts. Some patients feel as though people can hear their thoughts (thought broadcasting), that their thoughts have been taken (thought withdrawal) or that they can read other's thoughts (mind reading). With delusions of guilt, patients may feel responsible for some terrible act(s). Some also have grandiose and religious delusions. Disturbances in language are also found in some individuals; these symptoms are grouped under the category of thought disorder and involve loose associations or derailment, tangentiality, and incoherence. Thought disorder symptoms fit into our framework also, but will not be discussed as extensively here as other symptoms (the language domain in will be discussed in more detail in a subsequent manuscript). Patients can also present with decreased, slowed or bizarre motor, and speech responding. For a detailed and complete list of symptoms, see the Scale for the Assessment of Positive Symptoms or SAPS and the Scale for the Assessment of Negative Symptoms or SANS (Andreasen, 1981, 1984). Frequently cited or core cognitive deficits are those of working memory and verbal declarative memory (Goldman-Rakic, 1994; Kuperberg and Heckers, 2000; Seidman et al., 2003) as well as attention (Elvevag and Goldberg, 2000). Several investigators have also identified cognitive aspects that seem to be abnormal in schizophrenia, and these will be addressed in our review (e.g., abnormal salience detection, abnormal efference feedback, and abnormal errordependant updating of inferences - see Kapur, 2003; Fletcher and Frith, 2009; Whitford et al., 2012). 


\section{THE RELATIONSHIP BETWEEN AN UNDERSTANDING OF THE PHENOMENOLOGY AND THEORETICAL EXPLANATIONS OF THE SYNDROME: REFRAMING THE SYMPTOMS AND COGNITIVE DEFICITS OF SCHIZOPHRENIA}

The seemingly diverse cognitive deficits and symptoms described above have led investigators to posit either abnormalities in higher level executive function involving the dorsolateral prefrontal cortex (DLPFC); or to posit widespread abnormalities in gamma, cognitive dysmetria or cortical inefficiencies (e.g., Goldman-Rakic, 1991; Andreasen, 1999; Kapur, 2003; HeinksMaldonado et al., 2007; Tseng et al., 2007; Fletcher and Frith, 2009; Powell et al., 2012). For example, one class of theories posits problems with corollary discharge (from DLPFC to auditory cortex for example) and a failure to ignore stimuli because they are not tagged as self-generated-so actions and thoughts are judged to be arising from someone else and they are more salient (Heinks-Maldonado et al., 2007; Fletcher and Frith, 2009). A second problem with probabilistic reasoning and belief formation (based on frontal lobe) is then postulated to account for delusions (Fletcher and Frith, 2009). A schizophrenic deficit in anterior cingulate and error detection or cognitive control (as in the Stroop task) and then a failure to engage the DLPFC to resolve the conflict has also been proposed (Carter and van Veen, 2007).

These theories do not directly address negative symptom formation and may not be able to account for some positive symptoms such as visual hallucinations or hearing voices conversing with each other.

Ultimately any account of schizophrenia must address key components of the disease including the prodromal signs, the particular form or content of the symptoms (e.g., that visual hallucinations consist of humanoid forms), the relative prevalence of symptoms, the cognitive deficits, and the onset in late adolescence. Although many current theories postulate widespread brain abnormalities, the syndrome of schizophrenia is distinct from other neurological conditions (e.g., Parkinson's disease) and the patients present with a specific cluster of symptoms and prodromal perceptual disturbances.

As described above, most current theories are based on the implicit assumption that the functions affected in schizophrenia are disparate and diverse. Widespread abnormalities or multiple sites of dysfunction may be at the core of the disease. However, in the current framework, the symptoms, and cognitive deficits are seen as different aspects or consequences of the same dysfunction within a core system. The syndrome can be reconceptualized as the aberrant functioning of a system that is used for social communication and I will describe how this then provides a unified explanation of the symptoms and cognitive deficits. The overlap of function in this system reflects the overlap of functions that are used during social communication. For example, audiovisual speech and visual-tactile gestures occur simultaneously during social communication and are both represented in either an overlapping or adjacent way in this system. The core abnormality underlying hallucinations, delusions, negative symptoms, and cognitive deficits is proposed to stem from overactivation in a circumscribed posterior region (PSTS/TPJ) in either the same or adjacent neurons or circuits. Evidence will be described showing that the syndrome arises from this system. The framework described here also provides a link between proposed molecular/neurotransmitter/genetic abnormalities found in schizophrenia and the phenomenology which arises from properties at the brain systems level of analysis. Abnormalities in $\mathrm{N}$-Methyl-D-Aspartate receptor function (NMDA), gammaaminobutyric acid (GABA), or the interaction of the two have been proposed to underlie the syndrome (Lewis et al., 2005; Coyle, 2006; Rujescu et al., 2006; Javitt, 2009; Woo et al., 2010). These abnormalities may differentially affect the hippocampal system and possibly the magnocellular processing streams (discussed below).

\section{HIPPOCAMPAL INVOLVEMENT IN SCHIZOPHRENIA}

There is overwhelming converging evidence for the involvement of the hippocampus in schizophrenia (e.g., Bogerts et al., 1985; Brown et al., 1986; Manchanda et al., 1993; Heckers et al., 1998; Heckers, 2001; Seidman et al., 2003; Ghose et al., 2009; Heckers and Konradi, 2010; Williams et al., 2010). The hippocampus undergoes changes in adolescence (frequently the onset of schizophrenia) and has unique qualities related to sex hormones as well as stress hormones. It is hypothesized that aberrant activity from the hippocampal system produces psychotic symptoms. In the field of neurology, there is an extensive literature showing that patients with temporal lobe epilepsy (with the focus in the hippocampus) can sometimes develop psychosis (reviewed in Devinsky, 2008). The following quote from Elliott et al. (2009) alludes to this association between hippocampal activity and psychotic symptoms: "Postictal psychosis is noted for its similarity to schizophrenia-like/paranoid and affective psychoses and there is convincing SEEG evidence that, for some cases at least, the psychosis is not in fact postictal but rather an ictal psychosis due to ongoing limbic seizure activity and a form of non-convulsive status epilepticus.... There is convincing SEEG evidence of frequent, semi-continuous and sometimes continuous epileptic activity in limbic structures at the time of psychotic and hallucinatory ideation and behavior, suggesting that in some cases at least, the epileptic activity is the cause of the symptoms." Note that the hippocampal system is the most frequent site of epilepsy.

NMDA and/or NMDA/GABA abnormalities have been proposed to play a key role in schizophrenia, and drugs that act on NMDA receptors such as phencyclidine or PCP mimic the symptoms. These drugs seem to exert a differentially large effect within the hippocampus (Olney and Farber, 1995; Coyle, 1996, 2006; Bogerts, 1997; Benes, 1999; Olney et al., 1999; Tamminga et al., 2003; Benes et al., 2007; Javitt, 2009; Woo et al., 2010).

A recent high resolution study measuring cerebral blood volume in prodromal individuals showed that CA1/subiculum (the input/output layers of the hippocampus) hyperactivity uniquely predicted conversion to psychosis and that this activity was correlated with clinical symptoms (Schobel et al., 2009). Conversion to psychosis was not predicted by activity in the other regions measured such as amygdala, DLPFC, basal ganglia, gyrus rectus, or medial orbitofrontal cortex. Importantly, analyses on this human dataset and studies using mice confirmed that medication did not mediate this effect. The subiculum undergoes a "striking" increase 
in myelination during late adolescence corresponding to the onset of schizophrenia; the changes during adolescence were far greater than in other brain regions that were examined, including the anterior and posterior cingulate cortices (Benes, 1989). In this report, it was also noted that the myelination of the prefrontal cortex did not undergo a striking change in adolescence. This increase in myelination in the output layers of the hippocampus could increase the likelihood of aberrant hippocampal activity affecting other areas such as the TPJ (note that the inferior parietal region also undergoes myelination in adolescence-this is discussed below).

The CA1 layer of the hippocampus is differentially sensitive to excitotoxic damage relative to other brain areas. Anoxic/ischemic episodes can cause circumscribed damage to only the CA1 region in adults resulting in an amnesic syndrome (Zola-Morgan et al., 1986). The CA1 layer has the highest concentration of NMDA receptors and glucocorticoid or stress hormone receptors in the brain, conferring high levels of plasticity (e.g., long term potentiation or LTP) and also vulnerability to excitotoxic mechanisms (Cotman, 1987; Sapolsky, 1994; reviewed in Wible et al., 1997). LTP increases the likelihood of an action potential at a synapse and hence increases excitability. PCP blocks NMDA receptors but paradoxically acts to excite neurons. PCP may achieve this effect by blocking recurrent inhibitory pathways more strongly than the main excitatory pathways, leading to the disinhibition of pyramidal neurons and resulting in excitation (Grunze et al., 1996). The symptoms of PCP intoxication are similar to both the positive and negative symptoms of schizophrenia (Javitt, 2007). CA1 may also be relatively prone to excitation due to abnormalities in GABA interneurons, which are 10 times more sensitive to NMDA receptor inhibitors than pyramidal neurons, and which exert an inhibitory tone on neural activity (Grunze et al., 1996). GABA abnormalities have been found in the hippocampus in schizophrenia and bipolar disorder (e.g., Heckers et al., 2002). The hippocampus also contains high concentrations of $N$-acetylaspartyl glutamate (NAAG), which is released with glutamate and selectively blocks LTP of recurrent inhibition that is mediated by NMDA receptors on GABA interneurons (Coyle, 2006). Increased levels of NAAG in schizophrenic brains might also be responsible for use-dependent excitotoxic damage or oxidative stress damage, and the behavioral symptoms of schizophrenia (Coyle, 2006).

Schizophrenia (as well as autism) may be more prevalent, have an earlier onset and a more severe course in males than in females (e.g., Nicole et al., 1992). The hippocampus is one of the most sexually dimorphic regions in the brain and this feature could result in differential vulnerability to psychosis in males. Testosterone has been shown to affect memory and testosterone and estradiol levels in the hippocampus may be regulated independently of levels in the body (Schulz and Korz, 2010). Sex hormones may regulate neurogenesis in the hippocampus (Gould et al., 2000). Stress hormones may also interact with testosterone function (Ward, 1984; Ward and Reed, 1985). Hippocampal physiology is tied to the action of some schizophrenia associated genes such as DISC1 and ZNF804A (Meyer and Morris, 2009; Lencz et al., 2010; Ayhan et al., 2011). In summary, the hippocampal system is relatively vulnerable to excitotoxic damage and to psychological stress, the major output pathways undergo myelination in adolescence (when schizophrenic symptoms appear) and the hippocampus is especially sensitive to hormonal influences that are changing during adolescence. Thus, hippocampal dysfunction may provide a touchstone for understanding how a diverse set of genetic and developmental factors could produce schizophrenia. Hippocampal over-activation has been known to exist and has been replicated for a number of years; what is missing is an understanding of the consequences of such over-activation. Schizophrenia may result from an interaction between environmental factors and a genetic predisposition that is present from birth. Over-activation of the hippocampal system could stimulate other brain regions resulting eventually in excitotoxic damage both to the hippocampus and to regions whose activity is highly correlated with hippocampal activity.

\section{HIPPOCAMPAL ACTIVITY IS CORRELATED WITH ACTIVITY IN THE TEMPORAL-PARIETAL JUNCTION}

Resting state hippocampal connectivity is highly correlated with TPJ activity and hence over-activation of the hippocampus should be coincident with over-activation of the TPJ; regions showing high connectivity with hippocampal activity are shown in Figure 2 from Vincent et al. (2006); see also Kahn et al. (2008). Consistent with these connectivity findings, the posterior superior temporal and inferior parietal regions are efferent targets of the hippocampus (Rockland and van Hoesen, 1999; Clower et al., 2001). Hippocampal amnesia affects social functioning and was found to disrupt the creative use of language during social interaction (Duff et al., 2009). NMDA abnormalities might be expected to exert a relatively large influence on this region both through its high connectivity with the hippocampus and its putative involvement in magnocellular processing (see below). It is proposed that the regions showing high connectivity with the hippocampus are involved in psychiatric disease and that TPJ-hippocampal interaction may produce the preponderance of schizophrenic symptoms and cognitive deficits. Note that others have shown abnormal activity in schizophrenia in portions of the brain showing high connectivity with the hippocampus (e.g., Whitfield-Gabrieli et al., 2009). These abnormalities may be fully manifested when myelination and exposure to hormones converge in adolescence. There is indirect evidence for hippocampal-TPJ abnormal connectivity in the form of overactive default mode findings in schizophrenia (e.g., Garrity et al., 2007; Harrison et al., 2007; Zhou et al., 2007). In a resting state analysis, a seed placed in the hippocampus will reveal activity in many of the major neocortical regions constituting the default network (Vincent et al., 2006). However, direct investigations of this "hippocampal network" have not yet been performed.

\section{THE REPRESENTATIONAL STRUCTURE AND ARCHITECTURE OF THE TPJ REGION MATCHES ESSENTIAL ASPECTS OF THE SCHIZOPHRENIC SYNDROME: AN OVERVIEW AND A DESCRIPTION OF THE LOGIC AND ASSUMPTIONS UNDERLYING THE FRAMEWORK}

The representational structure and functional architecture of the TPJ will be reviewed to reveal how it is related to the diverse symptoms of schizophrenia. Functional regions have been identified which play a core role in dynamic social communication 


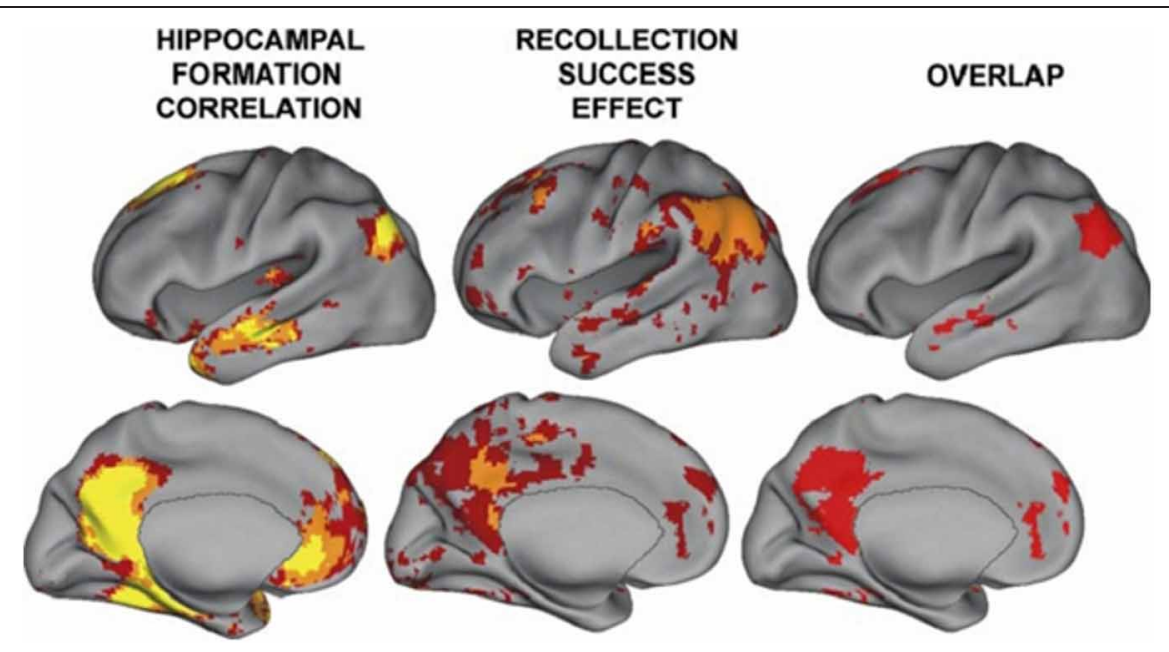

FIGURE 2 | From Vincent et al. (2006); regions correlated with hippocampal activity in resting state (note that activity is bilateral). These regions overlap with those showing activity related to recollective success. Figure 8 from the paper Vincent et al. (2006). Disclaimer: this is an unofficial adaptation or translation of an article that appeared in a publication of the American Physiological Society. The American Physiological Society has not endorsed the content of this adaptation or translation, or the context of its use. and interaction. Recent evidence shows that in humans these representational systems are housed to a large extent within the TPJ/PSTS territory and are used in dynamic gesture perception and production (including audiovisual speech), agency perception, theory of mind, bottom up attention, social attention, and emotional perception/reaction (see Blanke and Arzy, 2005; Decety and Grezes, 2006; Decety and Lamm, 2007; Redcay, 2008; Wible et al., 2009b; Wible, 2012). For example, Redcay (2008) reviews the function of the PSTS as follows: "Thus, behaviors that engage the STS include attributing intentions to others, perception of a social form from sparse, moving information, perception of the changeable aspects of faces such as eye gaze and expressions, complex motion perception, prosody perception, and narrative comprehension, to name a few." Figure 3 shows the overlap of functional areas related to several of these functions (note that most of these functional regions are bilateral; only the right hemisphere is shown here).

The example of auditory hallucinations will be used illustrate the logic for understanding the links between symptoms and the brain that is used in the current framework. For the sake of parsimony, I assume that auditory hallucinations or hearing voices (the most prominent symptom) must activate at least some of the same regions used to perceive voices. In the same way, I posit that other symptoms must reflect activity within those regions related to the content of the symptom. In non-psychotic patients with visual hallucinations, the form of the hallucination matched the functional processing of the cortical regions that were activated during the experience of the hallucination; color hallucinations resulted from activation in color regions, visual object hallucinations resulted from activation in regions representing visual objects, etc. (Ffytche et al., 1998; Santhouse et al., 2000). Therefore, it is proposed that schizophrenic symptoms are a result of over-activation or aberrant activation in those regions whose processing and representational systems match the experience of the delusion or hallucination. In other words,

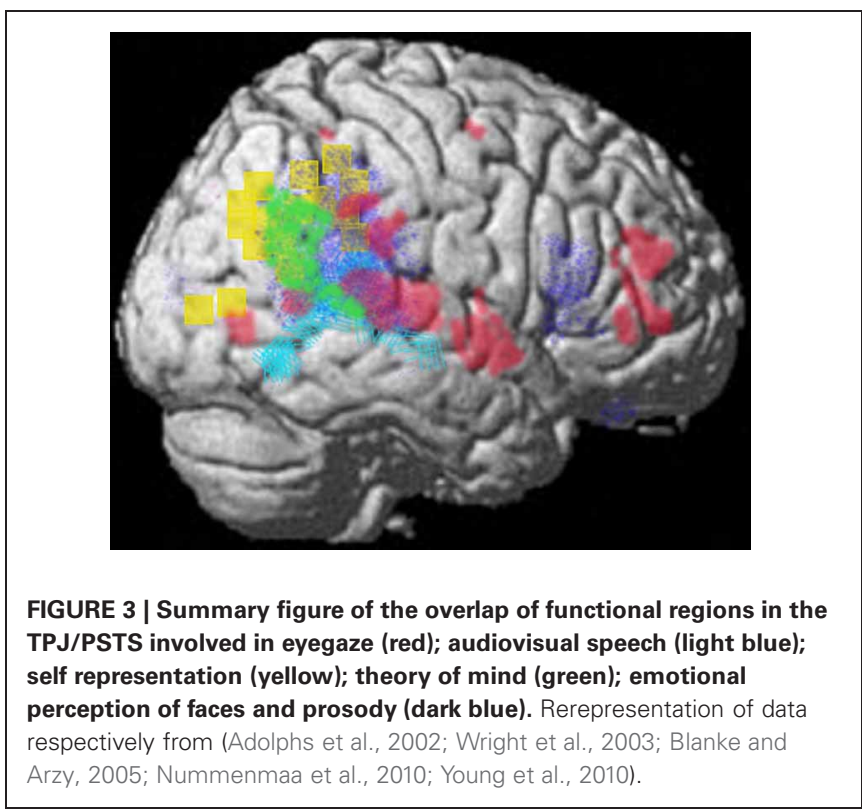

schizophrenic delusions and hallucinations stem from aberrant perceptual experiences. The idiosyncratic presentation or form of symptoms in patients is conceptualized as an attempt to make sense of the bizarre perceptual experiences. Maher (1974) put forward this hypothesis as illustrated by the following quotes "The patient is delusional because he is actually experiencing perceptual input that demands an explanation." “... the sensory quality of the experiences differs in vividness and intensity from the kinds of stimuli involved in normal misperception, and as the experiences are likely to be prolonged over considerable periods of time the machinery for reality-testing is itself impaired."

As described above, the most prominent hallucinations are the erroneous sense of a presence, voice or touch. The representation of dynamic gestures in the TPJ region is multimodal in the 
auditory, visual, and tactile domains and over-activation of these representations might underlie schizophrenic hallucinations. Inherent in the representation of dynamic gesture and person perception is the perception of agency and intention. So the over-activation of these gesture representations would produce the (erroneous) perception of agency and intention. This system for dynamic gesture processing is also used to perceive and produce emotional and attentional gestures, for self representation and the feeling of being an agent, for understanding other's intentions and thoughts, for language and narrative comprehension, and for forming intentions to speak and act. These functions might have counterparts respectively in the syndrome as deficits in the perception and production of emotional and attentional gestures (negative symptoms), problems with agency judgments (e.g., delusions of control), social cognitive deficits, and disorders of language (e.g., thought disorder, deficits in narrative comprehension). Hence, the prominent hallucinations and delusions of schizophrenia can be categorized as a misperception of a social presence as well as an accompanying misperception of intention and agency (e.g., someone is present, someone is speaking, observing, communicating, spying, acting, touching, persecuting, or controlling me). Several lines of evidence also show that the feeling of a presence and problems with agency attribution, as well as tactile hallucinations/delusions can also stem from a disturbance of the self-representation (described below).

\section{EVIDENCE FROM NEUROLOGY FOR TPJ AND HIPPOCAMPAL INVOLVEMENT IN PRODUCING PSYCHOTIC SYMPTOMS}

There are neurological conditions that result from frank brain damage where individuals exhibit symptoms that are similar to schizophrenia. Individuals with these syndromes can have delusions, hallucinations and denial of illness (lack of insight). The delusions can be fantastic and bizarre (as are those in schizophrenia). TPJ abnormalities are most often cited as the source of these conditions, with temporal lobe epilepsy (hippocampus) also sometimes present and thought to be a precipitating factor (e.g., Levine and Finklestein, 1982). Coltheart (2007) argues that delusional beliefs stem from an abnormality in sensory or motor function (as in inability to move a limb) plus damage to the right hemisphere and in particular to the frontal lobe which contributes the delusional aspects of the syndrome (Fletcher and Frith, 2009). However, lesion data from human subjects contradicts this conclusion and shows that although frontal damage is evident in some individuals with delusional syndromes, it is not necessary to produce the syndrome (e.g., Vallar and Ronchi, 2009). A recent review also posited that the inferior parietal region (part of the TPJ) is involved in schizophrenia and extensive evidence is presented for this theory, much of which will not be reiterated here (Torrey, 2007).

A circumscribed lesion of the TPJ or stimulation within this region is sufficient to produce delusions and hallucinations; stimulation of this region in humans can produce qualia such as feelings of a shadowy presence, of flying or being outside the body, of limb shortening/lengthening and hallucinations of complex visual and auditory scenes involving people (to name a few) (e.g., Peroutka et al., 1982; Blanke et al., 2002; Arzy et al., 2006; reviewed in Wible et al., 2009b). Within the neurological literature, damage to the right TPJ is often cited as the most frequent site involved in producing delusional syndromes concerning the body, with some patients showing symptoms that are indistinguishable from schizophrenia. Cummings (1997) makes the following observation: "Anatomically, lesions of the temporoparietal region are associated with the highest frequency of lesion-related psychoses (Levine and Finklestein, 1982; Peroutka et al., 1982; Miller et al., 1986; Berthier and Starkstein, 1987; Pakalnis et al., 1987; Rabins et al., 1991; Richardson et al., 1991).” Correspondingly, right inferior parietal activity was related to an active delusional state in a magneto encephalography (MEG) study (Ishii et al., 2006). Two patients with temporal lobe epilepsy were studied with MEG during a delusional state. Spikey activity in the right inferior parietal region was evident during the delusional state and disappeared when the delusions resolved. Geschwind (1965) describes the inferior parietal region as the association cortex of association cortex and notes that it is "... one of the last regions in which dendrites appear and that it matures cytoarchitechtonically very late, often in late childhood." This developmental maturation corresponds well with the onset of schizophrenic symptoms in late adolescence.

An overview of the dominant representational systems within the TPJ will be presented to set the foundations for understanding the relationship between sensory representation and higher order perceptual categories such as self versus other processing, agency, theory of mind, and social attention which have been shown to play a key role in schizophrenia. Cellular properties will also be described that correspond to aspects of the schizophrenic syndrome that have been noted by investigators.

\section{TPJ AND THE PERCEPTION OF OTHERS: MULTIMODAL BIOLOGICAL MOTION, PERSON PERCEPTION AND AUDIOVISUAL SPEECH PERCEPTION}

Social cognitive deficits are considered to be "...one of the primary determinants of functional outcome in schizophrenia." (quote from Javitt, 2009). Social perception has been defined as "...the initial states of evaluating the social communicative intentions of others by analysis of eye gaze direction, facial expressions, body movements, and other types of biological motion." (quote from Allison et al., 2000). Low level embodied representations (e.g., action-perception, somatosensory) may be used to make high-level inferences and judgments about intentions, thoughts, and desires of the self and others (Keysers and Gazzola, 2007; Lombardo et al., 2010). Evidence for this comes from single cell recording and neuroimaging data shows an intrinsic link between dynamic gesture perception and the perception of agency, intention, and social anticipation or prediction. This representational structure may be important for understanding schizophrenia.

Viewing biological motion in the form of gestures activates much of the lateral occipital temporal cortex as well as the PSTS, inferior parietal region, intraparietal sulcus, and supramarginal/precentral regions-see Figure 4 (Adolphs et al., 2000, 2002; Wheaton et al., 2004; Pelphrey et al., 2005; Nummenmaa and Calder, 2009; Pinsk et al., 2009; Nummenmaa et al., 2010). The PSTS, precentral gyrus and intraparietal sulcus are also activated during the imagination of biological motion (see Blakemore and Decety, 2001; Hein and Knight, 2008 for reviews). Lesions 


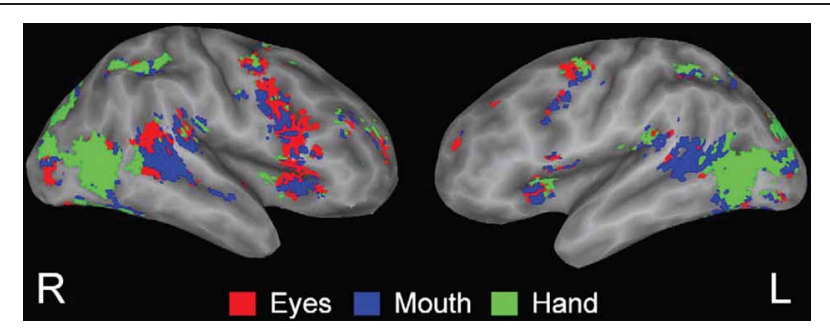

FIGURE 4 | From Pelphrey et al. (2005); Figure 3. fMRI activation related to viewing dynamic gestures; figures show activation from the condition showing the greatest response at each voxel (dark gray, sulcal depth; white, gyral crown). Red-the greatest response to Eyes, blue-Mouth, and green-Hand. Reprinted with permission from Pelphrey et al. (2005). (C) The Author 2005.

of the lateral occipital temporal regions impair biological motion recognition and repetitive transcranial magnetic stimulation (rTMS) to the PSTS impairs biological motion perception; hence, these regions are core substrates for the perception of biological motion in humans (Grossman et al., 2005; Billino et al., 2009).

The visual system may be organized into a ventral form processing pathway and a dorsal or magnocellular pathway that is specialized for processing movement and biological motion. Biological motion activates the PSTS approximately $20 \mathrm{~ms}$ before information reaches the ventral stream (e.g., fusiform). In the macaque, the dorsal pathway consists of V1,V3, medial temporal or MT, medial superior temporal or MST, which project then to the posterior superior temporal polysensory area or STP (in the monkey) and to parietal cortex (see Oram and Perrett, 1996). Earlier categorizations of these systems as the "what and where" visual streams may need to be reformulated; nonetheless the streams do differ in their processing characteristics (Schneider, 1969; Jellema et al., 2004; Milner and Goodale, 2008). The magnocellular visual pathway has been hypothesized to be differentially affected in schizophrenia because of this pathway's susceptibility to NMDA abnormalities (Foxe et al., 2001; Butler et al., 2005; Martinez et al., 2007; Chen et al., 2008; Vohs et al., 2008; Javitt, 2009).

Single unit recording and neuroimaging studies show activity related to form, motion and location within the STS in both humans and monkeys (Baizer et al., 1991; Oram and Perrett, 1996; Decety and Grezes, 1999; Blakemore and Decety, 2001; Karnath et al., 2001; Jellema et al., 2004). Puce and Perrett (2003) provided an extensive review of single unit (cell) recording studies in monkey STS and synthesized the findings with those from human subjects. The PSTS may be the human homolog of the macaque area STP, which is also sometimes called area TPO (Beauchamp et al., 2008). A population of cells in the macaque anterior STP (STPa) with large receptive fields respond selectively to the head and/or body independent of motion and also display size constancy and position invariance. These invariances may be used in higher order "person" identification. Cells have also been described that encode facial identity and expression; attributes that are also essential for representing persons and social interaction (see Oram and Perrett, 1996). There are cells in STPa that are selective for both form (seeing the body from a particular view) and direction of motion (see Oram and Perrett, 1996; Barraclough et al., 2005 for reviews). Hence, visual person (face/body) information is processed by "ventral stream" inferior occipital and fusiform gyri as well as anterior temporal regions which contribute biographical/person information (Gobbini and Haxby, 2007). These streams intersect in the human PSTS where visual motion, social/biographical, and speech domains come together (Puce and Perrett, 2003; Gobbini and Haxby, 2007).

The representation of dynamic gesture information in these areas is essentially multimodal (auditory, visual, and tactile); single unit recording in the monkey showed that audiovisual representation was the most prominent followed by visual-tactile and then trimodal response properties (e.g., Bruce et al., 1981). For example, neurons in the STS have been shown to be active to both the sight and sound of actions (Barraclough et al., 2005). The presentation of congruent auditory and visual stimuli can augment the single unit response by an average of $86 \%$ over visual stimulation alone (Barraclough et al., 2005). In addition, the territory activated for audiovisual speech gestures in humans (the PSTS/lateral temporal) occupies a significant portion of the PSTS (see approximate area in light blue in Figure 3) and these regions respond to both visual gestures and the speech sounds (e.g., Calvert and Campbell, 2003; Wright et al., 2003); see also the figure in Table 1 in Wible et al. (2009b). The predominance of voice hallucinations and visions of people, followed by tactile hallucinations fits well with this representational structure.

The integration of multimodal information within neurons in this system is proposed to form a basis for understanding action and may be used to anticipate and keep track of other's behavior without reference to the motor circuits that generate the action (Beauchamp et al., 2004; Barraclough et al., 2005; Beauchamp, 2005). Short term suppression is a phenomenon that occurs in neurons through-out the brain. Single neurons in the monkey STS exhibited a suppressed response to similar images for a short time. The activity of these neurons was selective for certain sequences of dynamic action, but not others, and this activity was dependant on the recent perceptual history. Hence, this activity dependant suppression results in "anticipatory" activity at the single cell level where the cells are actually tuned to detect inputs that are about to occur (Jellema and Perrett, 2003; Perrett et al., 2009). This anticipation or prediction is automatically computed without the need for motor simulation and is a natural property of the cells used to perceive the action (Perrett et al., 2009). These authors summarize the findings as follows: "We conclude that in a changing perceptual world, the values represented by cells' activities reflect a predicted future state rather than the present reality." Cellular activity that is tuned to "predict" could support the formation of expectations about other's impending behavior and may also be useful for keeping track of action and gestures (Jellema and Perrett, 2003). One surprising finding was that the responses of cells where an effective perceptual history was presented were also quite long (for some cells on the order of $10 \mathrm{~s}$ ). This sort of prolonged activation in response to dynamic gestures would have important consequences if the system were over-active as is proposed for schizophrenia. In addition to producing voice, visual person or tactile hallucinations, 
aberrant activity in this system would be expected to interfere with ongoing social/action perception and would affect the ability to track and understand gestures; it would also interfere with judgments about expectation.

Puce and Perrett (2003) review evidence from single cell recordings in the monkey STS showing that agency (intention, purpose) is represented at the single cell level and is an inherent part of the perceptual representation of dynamic gestures. The STS contains cells that combine information about reaching/grasping movements and about the attention or gaze direction resulting in a cellular representation of the intentionality of movements (Jellema et al., 2000). It was found that a few of these cells also showed extended responses (for example, $7 \mathrm{~s}$ ) that persisted after the movement was finished.

The perception of agency and intention from biological motion is also hypothesized to be one of the primary roles of the PSTS in humans (Schultz et al., 2004; Morris et al., 2008). Bilateral activation of the PSTS has been shown in several human neuroimaging studies in response to viewing the motion of shapes when the motion seems intentional (e.g., chasing) versus random (e.g., Pelphrey et al., 2004; Saxe et al., 2004; Schultz et al., 2004). In one study, the (left) PSTS was the only region of those activated by biological motion to respond differentially (increased activation) to motion that was perceived to be caused by the actor when compared to unintentional movement-caused by a piston moving the hand up and down (Morris et al., 2008).

Hence, hallucinations of people (or voices) should also be accompanied by the automatic attribution of intentions. This result was obtained in a study of brain stimulation using a human subject. Direct brain stimulation of the human TPJ caused the feeling of a shadowy presence, which the authors attributed to the stimulation of proprioceptive and tactile regions representing the patient's body (Arzy et al., 2006). This subject also attributed intentions to the shadowy figure: "He wants to take the card"; "He doesn't want me to read." Also note that stimulation of the lateral occipital temporal, superior temporal and planum temporale regions can produce visual hallucinations of action scenes involving people; these results illustrate that these regions may form the neural substrate for human action representation, memory and understanding (reviewed in Penfield and Perot, 1963; Wible et al., 2009b).

Multimodal information from the PSTS is passed on (via inferior parietal regions) to premotor regions. The parietal region is generally thought to be involved in integrating sensory information and transforming different coordinate systems into a common frame of reference for action planning or forming intentions for action (Andersen et al., 1997). The inferior parietal and ventral premotor regions contain mirror representations that are activated during either action observation or execution in both monkeys and humans (Buccino et al., 2001; Fogassi et al., 2005; Fujii et al., 2007). The posterior inferior and middle frontal regions are also activated by visual gestures (Pelphrey et al., 2005). The representation of these multimodal channels within a visuospatial framework and the coordination of different frameworks may also be important components of these representational systems; these properties may also be related to schizophrenic symptoms (see discussion in later sections).
The relative proportions of visual and auditory and touch responsive neurons in the PSTS region matches well with the proportion of hallucinations in the various modalities observed in schizophrenia. Auditory hallucinations (voices) were the most prominent, followed by visual hallucinations of humanoid figures. Tactile hallucinations are less prominent and olfactory hallucinations are even rarer. There are olfactory receptive areas within the IPS and TPJ, but these are relatively less prominent (Swisher et al., 2007). The realization that the perception of dynamic gestures is multimodal (auditory, visual, and tactile) and that it contains an inherent computation of anticipation, agency, and intention allows us to infer that hallucinations and delusions can result from the same mechanism and possibly from the same neural tissue or neural computations. Table 1 describes putative associations between abnormal activity and symptoms. Activation of this system in the absence of outside stimulation could lead to visual hallucinations of action gesture sequences, auditory hallucinations of voices, tactile gesture hallucinations or a feeling of a presence or gesture (being watched or followed). This aberrant activity would result in the perception of agency and intention when no entity is present. Interference with the social predictive or anticipatory activity of the neurons would be hypothesized to interfere with social cognition and reaction. The unconscious activation of gesture representations could lead to persecutory delusions and delusions of jealousy (feeling of action or presence of a person or people and the attribution of intentions to these entities). The unconscious activation of gaze gestures/head gestures (social attention gestures) could produce the feeling of being at the center of attention or being watched as is seen with delusions of reference. The unconscious activation of gesture representations could also lead to the misperception of agency for self-made actions (someone else is causing my actions as in delusions of control; someone else is causing my thoughts as in thought insertion).

Abnormal or over-active neural responses in these elements would affect both judgments about other's attention and the ability to perform attentional acts (as in delusions of reference, social inattention, and general attentional problems). A recent study of live face to face human interaction in conjunction with fMRI procedures showed that activity in the TPJ and the STS of human subjects was differentially recruited during joint attention-see Figure 1 (when compared to solo attention; Redcay et al., 2010). The dynamic perception of emotional and attentional gestures also partially overlaps with the regions that are involved in constructing motor plans/intentions for producing emotional and attentional gestures. This aspect allows for a conceptual link between abnormal dynamic gesture and prosody perception, emotion recognition, and abnormal social and emotional reactivity in schizophrenia (elaborated in later sections).

Prediction error, the mismatch between expectancy and experience, is thought to be a key abnormal element in schizophrenia by many investigators (e.g., Fletcher and Frith, 2009; Corlett et al., 2010). Anticipatory responsiveness at the cellular level within this system may participate in forming a neural prediction of self and others actions/gestures and abnormal predictive activity would interfere with producing a mismatch between expectancy and experience. 
Table 1 | Associations between symptoms, qualia, and brain dysfunction in schizophrenia.

\section{Prevalent schizophrenic symptoms and cognitive deficits-Qualia \\ Abnormal TPJ/PSTS function or overactive channel(s)}

Auditory hallucinations

I hear a voice or voices. I feel as though people are speaking to me

Visual hallucinations

I see a person or people. I see action scenes with people

Paranoid or jealous delusions

I feel the presence of a person with

(emotionally negative) intentions related to me

Delusions of reference

People are watching me. People are

communicating to me with their gestures.

Many things are salient

Delusions of mindreading, thought

broadcasting, thought withdrawal

Delusions of control

Someone is controlling me

Grandiose delusions, delusions of sin/guilt I am the cause of wide ranging events in my world. I am all powerful. I am responsible Attention deficits

Somatic hallucinations and delusions My body/face/hands/legs are abnormal

Affective flattening - unchanging facial expression, paucity of expressive gestures, poor eye contact and affective nonresponsivity, lack of vocal inflection

Cognitive deficit: impaired social cognition

Cognitive deficit: impairment in detection of disgust and fear in facial expression

Cognitive deficit: impaired working memory
Overactive Dynamic Audio-Visual Person/Gesture: Dynamic gesture representations are over-activated. Note that this may also cause abnormal processing of social prediction, intention, and agency as these are components of dynamic gesture representation

Attentional High-jacking: Overactive gesture information high-jacks attention through gamma synchronization of primary regions (e.g., auditory, visual, and tactile regions; in this case more for auditory cortex)

Increased Saliency: Feed-forward of abnormally active dynamic audio-visual gesture information to IPS saliency computation

Overactive Dynamic Visual Person/Gesture + Attentional high-jacking (more for visual cortex) + Saliency

Unconscious overactive dynamic person/gesture (either scenes, whole body or eyes or tactile other/self representations leading to the "feeling" of a presence) + overactive dynamic emotional gesture (possible activation of areas of SII that underlie higher order sexual feelings-in del. jealousy) + intention, agency + saliency + attentional high-jacking. Note also that STS neurons used to perceive gestures are tuned to detect social threat. Over-activation of social threat representations would contribute to paranoia and jealousy

Unconscious overactive Dynamic person/gesture (eye gaze/face or body) + intention, agency + saliency + attentional high-jacking

Over-activation of theory of mind and voice representation for self and others. Unconscious over-activation of dynamic gestures (head and eyes). Confusion of self/other agency for thoughts Unconscious over-activation of dynamic visual person/gesture. Somatosensory Abnormalities in Agency Representation or Vestibular Abnormalities (hypoagency). Failure to activate the self-representation. Confusion between self and other representation

Hyper-agency. Over-activation of self representation

Attention high-jacked by abnormal activity in multimodal channels through gamma activation of primary regions and through activation of saliency representations in IPS

Overactive somatic representation in EBA or somatosensory/vestibular cortices. (Note that EBA, somatosensory, and vestibular cortex also participate in the perception of biological motion and agency). Over-activation of the self-representation. Overactive self gesture-vestibular representation high-jacks attention through gamma synchronization of primary regions (more for tactile regions)

Over-activation of the receptive emotional gesture regions (e.g., PSTS, somatosensory plus insula/amygdala) that are also involved in emotional gesture expression. The supramarginal (inferior parietal) and somatosensory cortex are used in prosody production and perception. Abnormal activity in the gesture/prosody perception and production channels would interfere with both perception and reaction

Abnormal activity in the gesture/prosody perception and production channels would interfere with both perception and reaction

Abnormal social gesture prediction activity would lead to social slowing and awkwardness. Abnormal co-activation of agency and intention (with gesture activation) causes abnormal social responses

Over activation of social threat representations

Overactive emotional gesture perception (e.g., PSTS, somatosensory plus insula/amygdala)

TPJ/PSTS are involved in the representation of working memory contents; over-activation of these regions would interfere with working memory

Symptoms, associated qualia and mechanisms. Examples of hypothesized mechanisms for producing the schizophrenic symptoms/qualia within the TPJ and PSTS. 
The perception of biological motion involves gamma band synchronization. Gamma band activity was elicited by biological motion in humans (in the form of point light displays) over parietal cortex and right temporal cortex; whereas viewing inverted point light displays only produced gamma band activity in early visual regions (Pavlova et al., 2004). Some investigators posit a central role for gamma band dysfunction (along with NMDA abnormalities) in schizophrenia; this is discussed in the next section (e.g., Lewis et al., 2005; Woo et al., 2010).

\section{DYNAMIC MULTIMODAL PERCEPTUAL MECHANISMS IN THE TPJ AND PSTS INVOLVE FEEDBACK TO PRIMARY REGIONS AND THE SYNCHRONIZATION OF ACTIVITY IN PRIMARY REGIONS}

Under naturalistic conditions, real world inputs to the TPJ/PSTS provide near simultaneous stimulation (e.g., audiovisual speech/speech gestures) to create and activate dynamic multimodal representations of others and of the self. When activated, multimodal representations (auditory, visual, and somatosensory) in the TPJ/PSTS provide rapid feedback input to sensory regions, and especially to the auditory cortex in animals and humans; this feedback is pre-attentive, bottom up, and occurs even under anesthesia (Foxe et al., 2002; Matsuhashi et al., 2004; Macaluso, 2006). Regions that were traditionally thought to be unimodal (sensory cortex) have been found to contain neurons that respond to other modalities. Traditional unimodal regions can be influenced by information from other modalities with very short latencies ( $30 \mathrm{~ms}$ after stimulus onset). An electrophysiological study with monkeys showed that the functional interaction (gamma band) between the STS and the auditory cortex increased in strength during the presentation of dynamic faces and voices relative to either type of stimulus presented alone (Ghazanfar et al., 2008). The sustained gamma band enhancement was also associated with an increase in neural activity in the auditory cortex. This effect has also been found for touch and sound (Kayser et al., 2005). fMRI signals in visual cortex and in multisensory parietal regions correlate or show high connectivity when visual and tactile stimuli are presented at the same location (Macaluso et al., 2000). It was also shown that visuo-tactile stimulation (when both were on the same side) could cause increased activity in the visual cortex. Connectivity analyses showed that this influence was through feedback from inferior parietal multimodal regions (Macaluso et al., 2000). This is both an attentional mechanism (augmented processing within relevant channels) and a perceptual mechanism that can facilitate processing during social interaction and dynamic real world situations.

The congruent presentation of audiovisual speech/facial gesture stimuli also produces supra-additive activity in the PSTS, visual cortex, and auditory cortex in humans (Calvert, 2001). The audiovisual presentation of emotional information conveyed by intonation and facial expression (relative to unimodal presentation) resulted in enhanced behavioral accuracy in a classification task (Kreifelts et al., 2007). This increased accuracy was related to increased fMRI activity in the posterior superior temporal gyrus and to enhanced connectivity between multimodal audiovisual regions and auditory and visual association cortex.
Gamma has been shown to be abnormal in the TPJ of first episode schizophrenic patients. They showed a reduction in stimulus-locked gamma synchrony in left temporal and parietooccipital regions (Williams et al., 2009). Upon retest two and a half years later, gamma synchrony was increased and the increase was related to progressive gray matter reductions in left temporal and parieto-occipital (as well as left frontal) regions.

Thus, in this review, it is assumed that in addition to the normally described perceptual categories (auditory, visual, tactile, olfactory, etc.) there are higher order constructed percepts that play a central role in how individuals experience reality. The term "constructed" denotes that the representation does not consist of the disparate activation of neural elements but rather of an extension of activation over time and across other brain regions. Dynamic social perception under naturalistic circumstances has been hypothesized to rely on this type of cross-modal phase modulation of information within different time frames (e.g., delta, theta, and gamma) in different perceptual channels (Luo et al., 2010).

The simple example of speaking with another person involves the dynamic integration of voice and prosody, word and narrative meaning, visual gestures, and past knowledge about the person (to name a few examples of representational categories that must be activated and perceived as a gestalt). Hence, these multimodal feedback processes provide a mechanism by which social context can direct attention, augmenting the salience or signal strength of speech sounds (Macaluso, 2006). Consistent with this type of constructive representational account of TPJ/PSTS function, patients with parietal lesions have difficulties with gestalt/contextual perception or putting the pieces of the perceptual landscape together (Coslett and Lie, 2008).

One interesting and counterintuitive aspect of the schizophrenic syndrome is that the level of auditory hallucinations is most highly correlated with the levels of visual and somatosensory hallucinations in schizophrenic subjects (unpublished observations from large FBIRN dataset). Auditory hallucinations were (among symptoms) the most highly correlated with levels of visual hallucinations $(r=0.47$; Wible and Molina, in preparation) and with somatosensory hallucinations (as well as global delusions). Abnormal feed forward influences or feedback from multimodal regions to auditory cortex, visual cortex, and somatosensory cortex could augment speech, visual and somatosensory sensations respectively, resulting in increased saliency of representations in these unimodal regions and contributing to producing hallucinations. A recent study showed that schizophrenics have deficits in multisensory integration that were correlated with negative symptoms (Williams et al., 2010). Patients who had both auditory and visual hallucinations (compared to in only one modality) were especially impaired.

As was reviewed above, the sensory aspects of dynamic perception (e.g., biological motion of the body and eyes; speech and narrative) may be inextricably linked to the more conceptual or higher order perception of intention, agency, and social attention (Blakemore and Decety, 2001; Decety and Sommerville, 2003; Decety and Grezes, 2006). There is also evidence that this process need not be (exclusively) tied to the activation of motor regions. Hence, the processes that are used for the perception of others 
may also be used in self representation (evidence for this will be reviewed below).

\section{SELF REPRESENTATION INVOLVES MULTIMODAL INTEGRATION WITHIN THE (RIGHT) TPJ}

Recently, there have been profound advances in the understanding of self representation. As mentioned above, the feeling of the presence of social entities can result from abnormalities of the self-representation. The feeling of the presence of an entity might also produce abnormal agency perception for self-produced actions and thoughts. Most of the components of the TPJ self representation are also used to represent others and use a multimodal code (described in this section). Hence, over-activation of auditory speech, visual gesture, or tactile representations would be expected to be concomitant with problems with self representation.

A derangement or dissociation of the self-representation may underlie several neurological conditions or syndromes and may result in symptoms that are similar (or in some cases identical) to schizophrenic symptoms. Self representation is composed or constructed from multisensory input from multiple channels including vestibular (inferior parietal and posterior insula), somatosensory, efference copy (primary motor-M1 and possibly other prefrontal regions), proprioceptive (extrastriate body area or EBA and possibly other regions), visuospatial perspective or gesture/action perception, as well as information from stored body schemata (see Blanke and Arzy, 2005; Tsakiris, 2010).
One theoretical view of how these multimodal inputs can create the self-representation is as follows from Tsakiris (2010): "First, a pre-existing stored model of the body distinguishes between objects that may or may not be part of one's body. Second, on-line anatomical and postural representations of the body modulate the integration of multisensory information that leads to the recalibration of visual and tactile coordinate systems. Third, the resulting referral of tactile sensation will give rise to the subjective experience of body-ownership. These processes involve a neural network comprised of the right temporoparietal junction which tests the incorporeability of the external object, the secondary somatosensory cortex which maintains an on-line representation of the body, the posterior parietal and ventral premotor cortices which code for the recalibration of the hand-centered coordinate systems, and the right posterior insula which underpins the subjective experience of body-ownership." (see Figure 3 yellow region, Figure $\mathbf{5}$ and Table $\mathbf{2}$ for self processing summary information). The information in Table 2 illustrates how aspects of self processing overlap with the processes involved in perceiving others and documents the multimodal nature of the representation. With regard to body ownership, the insula may play an important role in vestibular function that contributes the feeling of being the agent of movements. Craig (2009) posits that the insula is involved in the perception of self-made movements and thus may contribute to self-representation as well as emotional awareness: "the insular cortex contains a somatotopic representation of the subjective feelings of one's current movements as

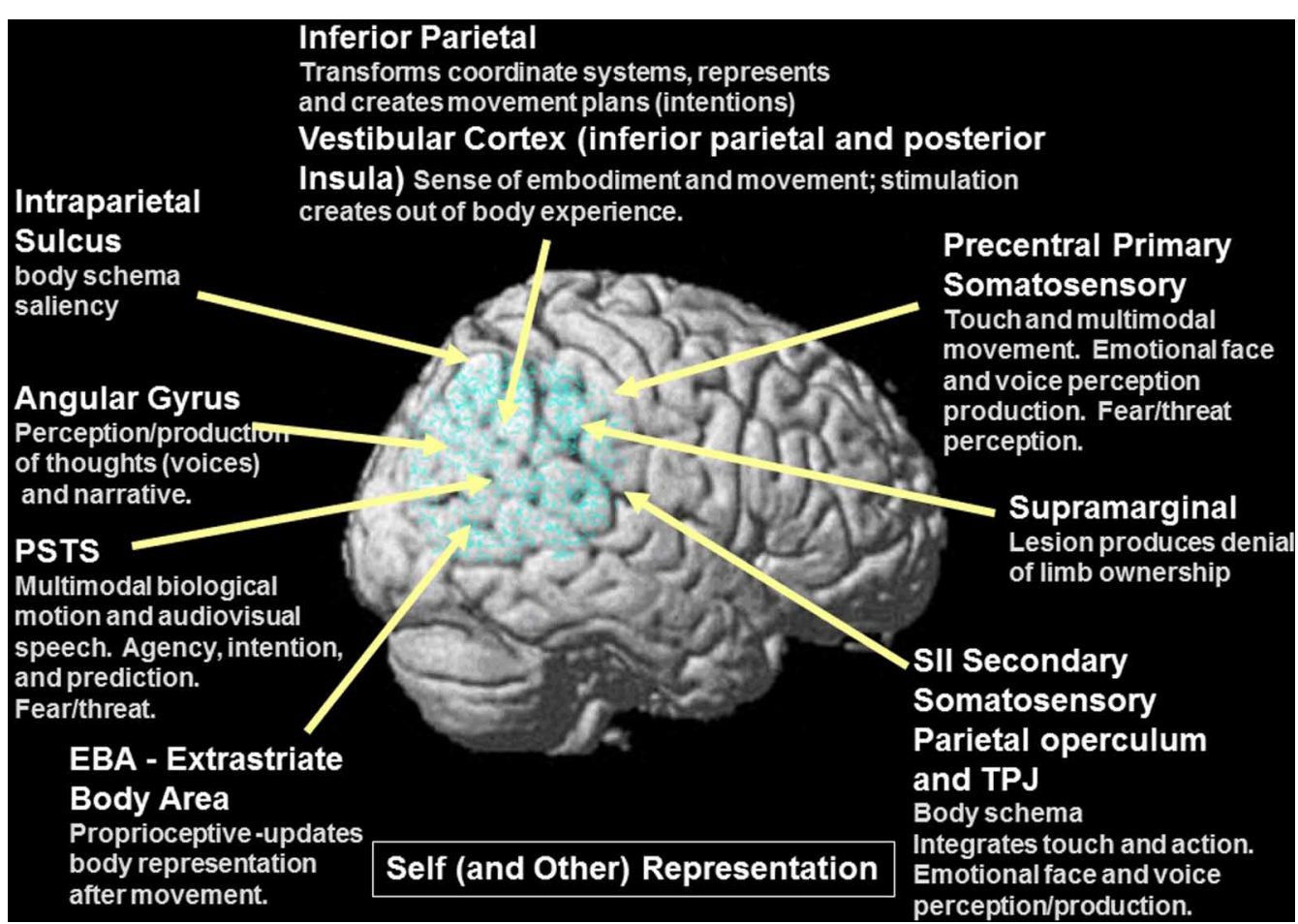

FIGURE 5 | Details of self representation and the overlap between self and other representation within the components of the system (gray font). Note the extensive overlap between elements of the system for self and other representation, movement and agency. Also note that the components of this system are multimodal (auditory, tactile, and visual). 


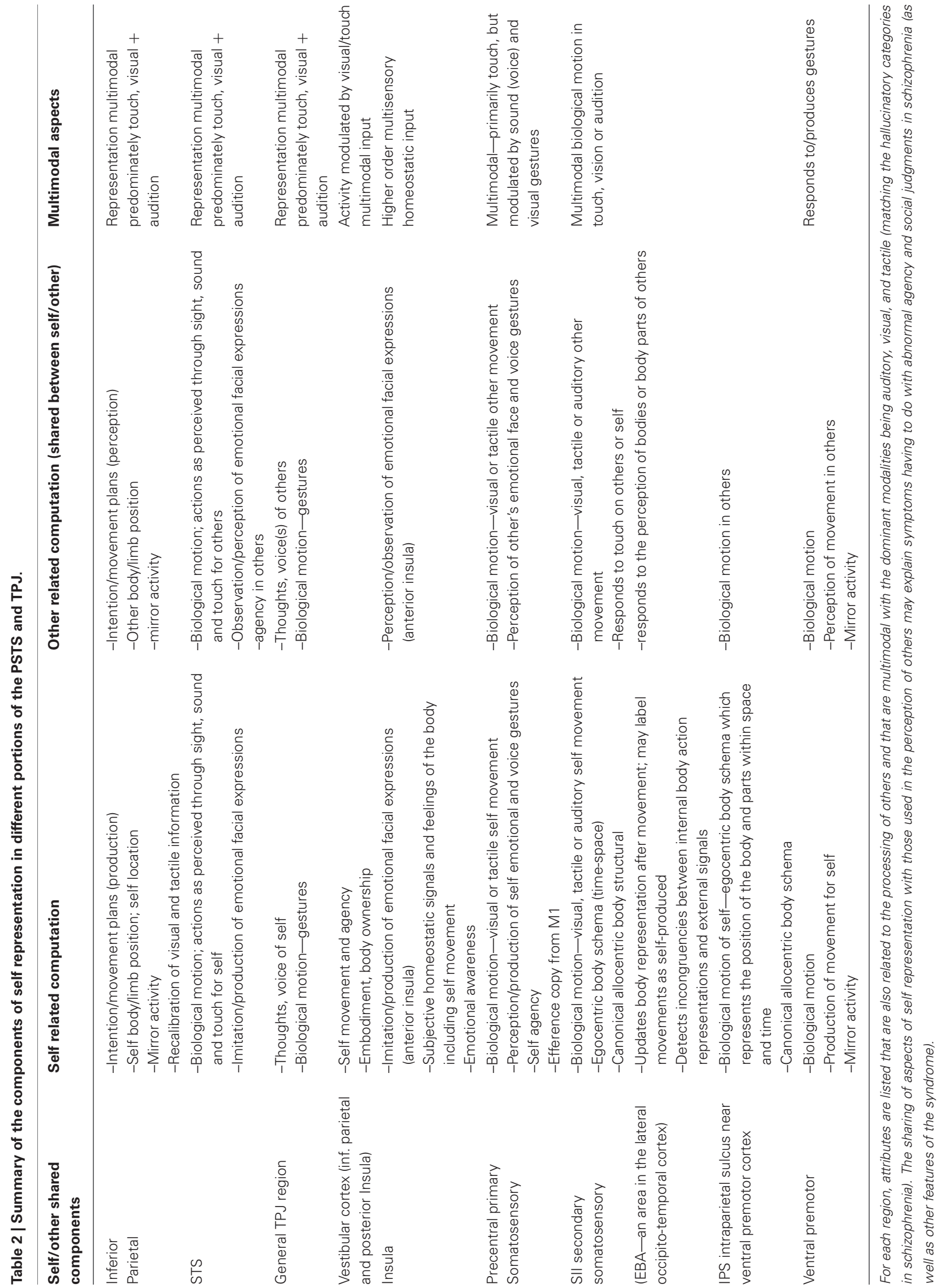


part of a representation of all feelings from the body." With regard to the stored body model, there may be both an egocentric body schema which represents the position of the body and parts within space and time and a more canonical allocentric body structural description with codes the position of each body segment within a standard body (reviewed in Corradi-Dell'Acqua et al., 2009). Neuroimaging has found both types of body representation in the intraparietal sulcus or IPS bordering on the inferior parietal region and ventral premotor cortex (CorradiDell'Acqua et al., 2009). A study explicitly comparing the two types of body representation found evidence for an egocentric body schema within secondary somatosensory cortex-SII and an allocentric or structural representation in the left IPS/superior parietal cortex (Corradi-Dell'Acqua et al., 2009). Recently, it was also found that the extrastriate body area which (EBA-an area in the lateral occipito-temporal cortex) updates the representation of the body after movement and may be important for labeling movements as self-produced (Astafiev et al., 2004). The activity of the EBA may reflect incongruencies between internal body action representations and external visual signals (David et al., 2007). The EBA was first found to respond to images of bodies or body parts. One theory of social inference states that the EBA detects animated motion and engages the PSTS to predict the goals and intentions from biological motion cues and from the identification of the agent by fusiform and anterior temporal regions. The deviation of the perceived motion from what was predicted produces a re-engagement of attention (McCarthy, 2010 Faces, Agents, and Animacy: Neurophysiological Studies of Social Perception. Talk given at BCS MIT on Friday March 19 2010).

These regions that may be involved in self representation are also activated during biological motion or seeing another person/body, including the TPJ, somatosensory cortex, SII, EBA, IPS, and ventral premotor regions (Wheaton et al., 2004; Pelphrey et al., 2005). For example, SII is used to integrate touch in different parts of the body (see Corradi-Dell'Acqua et al., 2009 for a summary). SII is not only sensitive to somatosensory information, but responds to moving stimuli that are perceived through touch, vision or audition (Bremmer et al., 2001). This area also responds to touch regardless of whether it was felt on one's own skin or seen on another (Keysers et al., 2004). Hence, like the dynamic representation of people and their movements, selfrepresentation is inherently multimodal and multimodal inputs within the TPJ/PSTS may play a large role in this function. In addition, evidence shows that the regions that are used to represent the self overlap with those that are used to represent others. See Figure 5 and Table 2 for a summary of this overlapping self/other representational system.

The constructive nature of the self-representation can be readily demonstrated by experimental manipulation as seen in phenomenon such as the rubber hand illusion and the body swapping illusion (see Tsakiris, 2010 for a review). Altschuler and Ramachandran (2007) published instructions for a simple demonstration of disembodiment than is done using mirrors and tactile stimulation; in this demonstration a lack of registration of touch and proprioception combined with the inability to see one's entire face produced the illusion. In another study, subjects were induced to feel as though they momentarily inhabited another body (Petkova and Ehrsson, 2008). Subjects stood face to face with an unclothed rubber mannequin and were outfitted with goggles so that their visuo-spatial perspective was that of looking down onto the mannequin's body, not their own body. Simultaneous touch to both the subject and the mannequin on the torso was sufficient to induce the illusion that subjects' bodies had been swapped with the rubber mannequin. This study shows that the feeling of ownership of the body or of embodiment is constructed from dynamic convergent multimodal input (in this case visual-spatial perspective and somatosensory input). Hence, this type of dynamic multimodal or constructed representation of the self can be disturbed by aberrant input from multi-sensory neuronal representations. In other words, the same over-activation that must be assumed to underlie the hallucinatory perception of a voice, person or touch should also affect the self-representation.

Image-guided rTMS was used to create a "virtual lesion" over the inferior parietal region (Uddin et al., 2006). This stimulation selectively disrupted performance on a self-other discrimination in healthy individuals providing strong evidence for this region's involvement in the representation of the self. A series of studies showed that in healthy individuals, a relative increase in TPJ activity concurrent with activation of the insula signals external agency (Farrer and Frith, 2002; Blakemore et al., 2003). In hypnotized subjects, the misattribution of movements to an outside source produced increased activity of the TPJ (and a lack of insula activity). This increased activity in the TPJ was also found in several studies of schizophrenic individuals with passivity symptoms or delusions of control (Spence et al., 1997; Franck et al., 2002; Blakemore et al., 2003; Farrer et al., 2004; reviewed in Wible et al., 2009b). Thus, the TPJ is involved in classifying movements (as well as ideas or thoughts) as external and in representing imagined movements and others' views or thoughts; this functionality may contribute to delusions of control, the misattribution of one's own thoughts to others, thought withdrawal, thought broadcasting, and social cognitive difficulties. Grandiose delusions, religious delusions and delusions of guilt may result from feelings of hyperagency [I am responsible for (creating, causing) many things] or from abnormal representations of embodiment and the extent or form of the body (e.g., $I$ have no bodily boundaries; I or my self is all encompassing or unified with the environment; I am one with the universe).

The phenomena of body swapping and the rubber hand illusion demonstrate the importance of simultaneous convergent information from several perceptual channels. Stimulation or brain damage that results in a disturbance in one or more of these channels (most often in the vicinity of the TPJ) can result in aberrant self-perception as in out of body experiences (OBEs) or autoscopy (seeing one's own body). OBE and autoscopy experiences are thought to result from either the breakdown of the integration of multimodal inputs or from discrepant inputs from proprioceptive, tactile and visual-spatial (visual perspective) channels (see Blanke and Arzy, 2005 for a review). For example, according to Blanke and Arzy (2005), OBE experiences consist of "illusory reduplication, illusory self-location, illusory perspective, and illusory agency." The convergent nature of the 
self-representation is demonstrated by the fact that both OBE and autoscopic hallucinations are influenced by the individual's position prior to the experience and hence are influenced by proprioceptive and tactile representations. Stimulation or damage in or near the TPJ can cause a type of autoscopy where the body double is not seen, but experienced as a "presence" or multiple "presences" (Brugger et al., 2006). Persecutory delusions, delusions of jealousy, and delusions of reference all involve this feeling of the presence of others. Hearing voices is also often accompanied by the feeling of a presence of entitie(s) within the body or mind. As previously discussed, the feeling of a presence might also interfere with agency signals or agency judgments for self-made actions and thoughts.

The vestibular channel in particular was thought to be important in OBE and vestibular sensations were evoked in a subject where higher levels of current induced an OBE (Blanke et al., 2002). The vestibular cortex may be located in the posterior insula and inferior parietal regions (Brandt et al., 1998). Vestibular neurons are themselves multimodal (they also respond to visual and somatosensory information) and constitute a channel of input to the self-representation (Grüsser et al., 1990). The vestibular system does not provide self movement cues under conditions of constant velocity; this is provided by large field visual motion cues. Interestingly, Brandt et al. (1998) found that the vestibular cortex in humans was inhibited by viewing radial flow information (radial flow of visual cues is experienced during movement). These observations show that even the most basic representational systems underlying the perception of agency are inherently multimodal and are based in the TPJ region. Note that overactivation in the system that normally represents visual radial flow would be expected to essentially shut down vestibular agency cues which would result in abnormal self agency judgments. This is an example of how perceptual categories (e.g., visual person perception and agency) that are affected in schizophrenia could be related at a mechanistic level.

Further evidence for parietal involvement in social interactions and for the overlap between self and other representation comes from a single unit recording study that was performed in two monkeys simultaneously (Fujii et al., 2007). In one condition, the monkeys were sitting across from each other but were not interacting. In a second condition, the monkeys were interacting with each other (there was food that either monkey could grab). Parietal neurons coded for the individual monkey arm position during the non-interactive condition. However, when the monkeys started to interact, the same neurons started to show complex activity related to both self and the other monkey's movements. Hence, aberrant activity could create problems with both self representation and agency judgments through a number of mechanisms.

Studies of human damage to the TPJ show that schizophrenialike symptoms can result from illusory perspective, illusory agency, and problems with self representation/embodiment. Somatoparaphrenia (Gerstmann, 1942) is a syndrome in which the limbs or body on one side are believed to be absent and are subject to illusions, delusions, and confabulations. In a review of several cases in the literature, Vallar and Ronchi (2009) show that for some patients, damage to the TPJ and/or insula is sufficient to cause the syndrome, a finding consistent with historical views of the syndrome (Nielsen, 1946; Critchley, 1953). According to Critchley (1953) there are several neurological manifestations of parietal disease, including the denial of hemiparesis; the belief that limbs are missing or belong to another person; and the belief that other's limbs are ones own. An analysis of patients with verbal asomatognosia (delusional denial of ownership of the limbs) versus those only showing only neglect (not delusional) showed that damage to the right inferior-posterior parietal or supramarginal gyrus and to the underlying white matter were the most frequent sites of damage followed by the insula, the lenticular nucleus, and the superior and middle temporal gyri (Feinberg et al., 1990). Vallar and Ronchi (2009) consider somatoparaphrenia to be a breakdown of multisensory integration and spatial representation of the self and body. Position sense and the awareness of the body within a spatial reference frame as well as vestibular input are thought to be central to the syndrome (Bisiach and Vallar, 2000; Vallar and Ronchi, 2009). Individuals with somatoparaphrenia can also present with visual hallucinations, illusory limb movements, somatosensory delusions and hallucinations, and delusions concerning the presence of people in the contralesional part of space (Feinberg et al., 2000; Vallar and Ronchi, 2009). All of these symptoms are also evident in the schizophrenic syndrome. In summary, evidence from neurological syndromes show that agency and self representation are linked and rely on neural substrates within the TPJ. Agency and self representation are also linked to the representation of others and damage to the neural representation of the self can lead to delusions and hallucinations concerning the presence of other people or confusion between self and other (see Table 2 ).

I discussed how circumscribed lesions of the TPJ or stimulation of this area in human subjects can produce delusions; these may stem from the stimulation or degradation of one or more of the input channels that together produce the self-representation. It is hypothesized that abnormal activity related to the constructed self representation may produce a number of symptoms in schizophrenia. This activity could produce a form of autoscopy where the patient experiences a "presence" or multiple "presences" resulting in persecutory delusions, delusions of reference or delusions of jealousy (someone is following me, observing me, with my wife). Delusions concerning the agency of thoughts and motor acts could also be a manifestation of abnormal self representation and could stem from any of the components of the system that normally convey self agency (e.g., delusions of control, delusions of mindreading, delusions of thought insertion, withdrawal, and broadcasting). Delusions of guilt/sin and grandiose/religious delusions may result from overactive feelings of agency or overactive self representation. Previously I discussed evidence for the involvement of these same regions in the representation of others (biological motion/gesture, intention, agency, and social anticipation); below I will discuss more evidence for this with an emphasis on emotional processing.

\section{DYNAMIC EMOTIONAL GESTURE PERCEPTION, VOICE PERCEPTION, AND EXPRESSION}

Schizophrenic individuals seem to be able to feel emotion, but are less expressive (e.g., Kring et al., 1993; Myin-Germeys et al., 
2000; Kring and Moran, 2008; see Mathews and Barch, 2010 for an alternative view and review). Over-activation in circuits used to detect emotional gestures would interfere with emotional perception and with emotional reaction. Schizophrenics are impaired in affect recognition and show reduced affective responsiveness. "Impaired facial affect recognition is a prominent feature of schizophrenia that is linked to negative symptom severity and poor functional outcome. These deficits are most prominent for the detection of threat-related emotions such as fear and anger..." (quote from Leitman et al., 2008). The negative symptoms of schizophrenia include affective flattening or blunting and are most often associated with a lack of facial expression, eye contact, and vocal inflection.

Emotional expression perception is associated with activity in the PSTS, the anterior insula, amygdala, and premotor cortex facial regions (see Decety and Grezes, 2006). Some single neurons in the STS of the monkey responded preferentially to facial expressions (see Barraclough et al., 2005 for a review). An fMRI study explicitly contrasted attention to the emotional expression with attention to identity (Narumoto et al., 2001). Face responsive regions were identified as the fusiform, right STS, and intraparietal sulcus. Attention to emotion enhanced the activity of the right STS compared with attention to the face. The human PSTS also participates in the perception of prosody (Wildgruber et al., 2005; Leitman et al., 2010). Lesions within the right primary/secondary somatosensory cortex, anterior supramarginal gyrus (part of inferior parietal cortex), insula and inferior motor regions interfere with the ability to perceive facial emotion and prosody (Adolphs et al., 2000, 2002; regions shown in Figure 6).

Viewing facial expressions, even when one is not consciously aware of them, creates a more subtle version of the expression on the viewer's face (Wallbott, 1991; Dimberg et al., 2000; Decety and Grezes, 2006). When subjects are required to either observe or to imitate (produce) emotional facial expressions, the STS, anterior insula, amygdala, and premotor cortex show increased activity (Carr et al., 2003). Collectively these data support the notion that the regions for perceiving emotional gestures in others overlap with those for planning reactions for response production. Hence dynamic emotional perception (facial and body gestures) and dynamic emotional responsiveness (especially of the face and eyes) are represented and executed by overlapping or adjacent circuits (Barresi and Moore, 1996; Decety and Sommerville, 2003). Thus, the PSTS and inferior parietal regions are involved in the

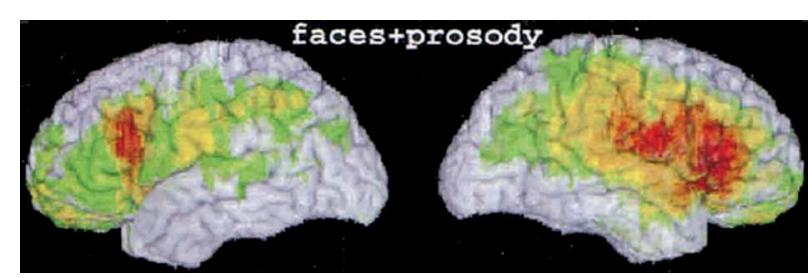

FIGURE 6 | Figure from a lesion analysis; regions damage in patients showing deficits in emotional facial expression perception and prosody perception (Adolphs et al., 2002-Figure 3b). Reprinted with permission from Adolphs et al. (2002). Copyright 2002 by the American Psychological Association, Inc. perception and production of emotional expression and prosody. Abnormal activity in these regions would be expected to interfere with emotional perception as well as reactivity (e.g., asociality, a paucity of vocal inflection, and facial expression).

Recent evidence shows that the right TPJ may be specialized for detecting dynamic emotionally negative or threatening gestures and may be even more important in this regard than the amygdala (see Figure 7). A recent study found that 2 patients with bilateral amygdala damage were not impaired in the recognition of fear from dynamic body expressions, leading to the conclusion that there are other regions that play a key role in this function (Atkinson et al., 2007; see also Marian et al., 2009; Cristinzio et al., 2010). In addition, damage to the amygdala (at least in adults) does not always change the subjective experience of fear (Phelps and Anderson, 1997; Kober et al., 2008). A study of brain damaged patients showed that the inability to recognize fear expressions was associated with damage to the inferior parietal/precentral region in the right hemisphere (Adolphs et al., 1996); this region is shown in purple in Figure 7. Evidence from ERP recording in humans and single unit recording in the monkey STS indicates that there is a neural bias for the detection of potentially threatening biological motion (see review in Perrett et al., 1985a; Oram and Perrett, 1994; Wheaton et al., 2001; Puce and Perrett, 2003). Hence, although single neurons in the STS are used to perceive dynamic gestures; they are tuned or biased for the rapid identification of threat. fMRI studies now show that dynamic and static facial and body expressions of negative emotions (e.g., fear) activate regions in the TPJ and premotor cortex more than neutral or positive emotions, especially on the right-see Figure 7 (Lotze et al., 2006; Grezes et al., 2007; Carter and Pelphrey, 2008). Note also that stimulation of the lateral occipital-temporal region results in hallucinations of complex (sometimes violent) visual action scenes involving people (discussed above). The symptoms of post-traumatic stress

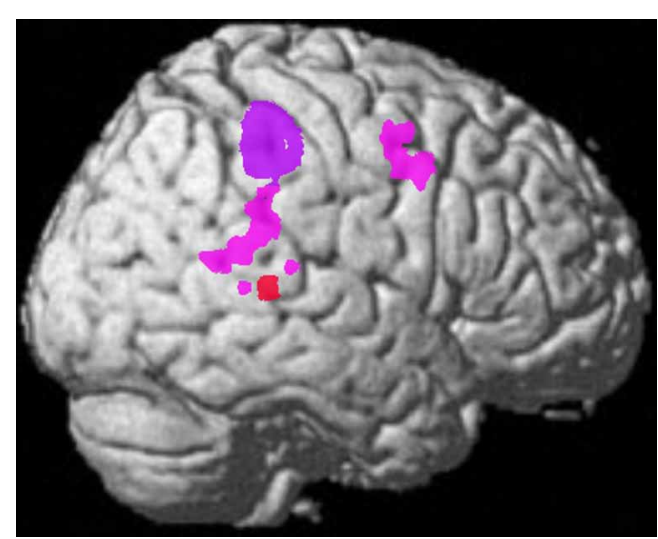

FIGURE 7 | Data from three studies of negative emotion. Red-fMRI activation in the right posterior STS was positively correlated with the perception of negative valence expressions from Lotze et al. (2006). Pink-fMRI activation of the right posterior temporal TPJ region is related to perceiving fear from body expressions re-representation from Grezes et al. (2007). Purple-core region where lesions in human subjects cause an inability to recognize negative valence expressions re-representation from Adolphs et al. (1996). Note also that activation of the right posterior STS is also related to jealousy (Rilling et al., 2004; Takahashi et al., 2006). 
disorder (PTSD) may result from hippocampal overactivation of the PSTS/TPJ as these regions are involved in threat-fear perception and in dynamic social memory. This would explain the dissociative aspects (self processing) of the disease as well as the flashbacks and other phenomenon.

It is hypothesized that the reduced emotional reactivity seen in schizophrenia is due to abnormalities in the circuits used to perceive dynamic emotional expressions and to produce intentions or premotor plans for action/reaction. In addition, because the system is tuned to detect threat, fear and threat related stimuli should be differentially affected. Hence, the regions that are used in dynamic emotional perception and reaction would be predicted to have abnormally high activity that would be related to symptoms such as persecutory delusions, delusions of jealousy and flat affect; individuals with these symptoms should also show reduced activity in subtractive neuroimaging studies (and perhaps reduced perceptual capabilities) during the perception of dynamic negative emotions (because activity is increased in the baseline in these regions). The negative or frightening tone of some symptoms may arise from the fact that over-activation may produce the feeling of being in a socially threatening situation.

Most of the studies of emotional perception have used static stimuli and many have documented abnormalities in schizophrenia (see discussion of controversies in Russell et al., 2007; Carter et al., 2009). A well-controlled study of facial emotion recognition showed that schizophrenic subjects were more likely to identify neutral facial expressions as having a negative valence (Kohler et al., 2003). In that study, schizophrenic subjects showed a reduced ability to recognize emotions, but were specifically impaired in recognition of fearful, disgusted, and neutral expressions. Abnormal threat perception in schizophrenia has also been a consistently replicated finding (Gur et al., 2007; Russell et al., 2007; Hall et al., 2008). Over-activation was found to interfere with affect recognition (for anger and fear or threat related emotions) and to be correlated with levels of flat affect (especially for fear; Gur et al., 2007). A further analysis of the regions producing neural responses to static fear processing showed abnormally higher correlations (using CORANOVA) between occipital and superior temporal regions in schizophrenic subjects (Leitman et al., 2008). A subsequent study of threat expression in faces showed that higher levels of symptoms were related to increases in limbic threat related responses and decreased recognition memory related responses in cortical regions suggesting that threat related processing may interfere with cognition in schizophrenia (Satterthwaite et al., 2010). Hence these findings support our supposition that overactivity in this system for perceiving and producing dynamic emotional gestures can interfere with social/emotional perception and with reactivity (resulting in flat affect). This part of the framework is unique in specifying concrete links between emotional reactivity and the differential difficulties with threat related emotions in schizophrenia.

One study found direct evidence for the link between emotional reactivity and emotional perception in schizophrenia. Among negative symptoms, the levels of flat affect uniquely predicted performance on emotional perception/differentiation tasks (Gur et al., 2006). Affect (face/voice) recognition was also found to be related to measures of social functioning in schizophrenia (Hooker and Park, 2002). A lack of expressivity in schizophrenia was associated with poor social competence and with impaired understanding of others' minds or theory of mind in another study (Brune et al., 2009). Hence, just as emotional expression and perception overlap at the neural level, perception and expression dysfunction are both found in the schizophrenic syndrome and may result in social cognitive and theory of mind deficits in these individuals as well as deficits in affective reactivity (flat affect and facial non-responsiveness).

In summary, evidence was presented showing that the perception of fearful body/face expressions involves the right PSTS, inferior parietal and precentral regions (see Atkinson and Adolphs, 2005 for a review). Dynamic emotional perception is subserved by the TPJ, the anterior insula and adjacent premotor regions (as well as the amygdala). Although it is used in the perception of all emotions, this dynamic system is biased to detect threatening stimuli. This bias may at least partially explain the propensity of negative or threatening experiential delusions seen in schizophrenia. For example, one study found that deluded schizophrenic patients were more likely to attribute an emotional bias to neutral stimuli in one study using words (Holt et al., 2006). As would be predicted by this framework, the perception of threat related emotions is particularly impaired in schizophrenia. In addition, the abnormal perception and production of emotion was found to be related to social function and theory of mind as would be predicted from the overlap of these functions within the TPJ.

Over-activation of the hippocampus might also cause abnormally high activation in the amygdala (because they are adjacent) and this may additionally bias the abnormal experiences by contributing a negative emotional tone. Overactive face/body gesture representations would be predicted to contribute a "feeling" of threat or of being in a socially fearful situation. If these neural elements are tuned to detect threat, then over-activation of these regions may mimic the activation inherent to real life social threat and may signal to the person that they are in a threatening situation. This may produce symptoms such as delusions of reference and persecutory/paranoid/jealous delusions (Wible et al., 2009a). The right TPJ has also been implicated in the processing of desire (Saxe and Wexler, 2005) and right PSTS activity uniquely correlates with jealousy and male sexual competition in humans and monkeys (Rilling et al., 2004; Takahashi et al., 2006). The systems for detecting and reacting to social threat and sexual competition may be linked because of our evolutionary history; the behaviors are linked in non-human primates and other animals. Hence it is hypothesized that overactive gesture representations in the TPJ could also result in delusions of jealousy. These conjectures are consistent with descriptions of subjective experience from patients; see this quote from Chadwick (2007): “... the-so to speak-'volume control' on my emotions of anger, fear, and sex seemed to be as if turned up too high. I found I was forever trying to tranquilize myself. The high anger and fear not only operated as basic drives but also produced a very punitive conscience." This quote also suggests that over-activation of this system whose activity is tuned to perceive social threat and is involved in sexual competition might contribute to delusions of sin/guilt. 


\section{GAZE PERCEPTION AND SOCIAL ATTENTION}

In addition to conveying emotion, dynamic gestures of the head and eyes convey the focus of attention and may aid in representing other's intentions and thoughts (Perrett et al., 1985b, 1992; Kleinke, 1986; Baron-Cohen et al., 1997; Allison et al., 2000; Emery, 2000). Hence dynamic representations of emotional gesture and attention may be used in processing and perceiving more conceptual aspects of social cognition (Baron-Cohen et al., 1997; Morris et al., 2008). Damage to the posterior superior tempo$\mathrm{ral} / \mathrm{PSTS}$ and inferior parietal regions impair the perception of gaze direction and attentional orienting from gaze showing that they are core substrates for these functions (Boddaert et al., 2004; Akiyama et al., 2006). These regions form part of a "ventral" attention system (Corbetta et al., 2008; Nummenmaa et al., 2010). A recent report (Nummenmaa et al., 2010) used psychophysiological interactions (PPIs) to identify regions showing differential connectivity with core face perception structures when viewing gaze shifts relative to a control condition (blinking). This technique identified regions (within a core face processing network) that showed a change in connectivity when individuals viewed gaze shifts as opposed to blinks. The regions identified are shown in Figure 8 and include a system in red identified from a seed in PSTS (MT/V5, PSTS, intraparietal sulcus, frontal eye fields (FEF), STG/STS, supramarginal gyrus and middle frontal gyrus) and a system in blue identified from a fusiform seed (fusiform gyrus, STG/STS and middle frontal gyrus) with the overlap of the two systems shown in green. Gaze perception is modulated by emotional gestures. Angry faces are more likely to be perceived as having a direct gaze or as looking at the subject when compared to fearful or neutral faces (Ewbank et al., 2009).

Gaze representations could act to guide attention and to produce the gamma synchronization of more primary cortical regions as was reviewed above. In the complex and multi-layered natural environment, attentional guidance through gestures may be thought of as part of the act of perception, because without this automatic computation, perception during social interaction might become overwhelmed and break down. These concrete/embodied

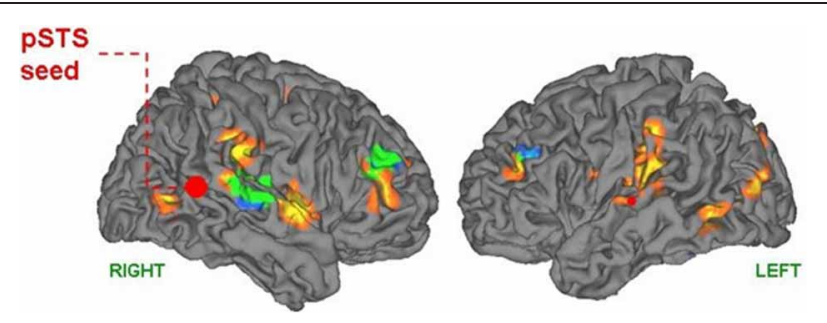

FIGURE 8 | Results from an fMRI study of gaze processing; figure from (Nummenmaa et al., 2010). That study used psychophysiological interaction to identify regions showing differential connectivity with core face perception regions (either PSTS or fusiform or both regions) when viewing gaze shifts relative to a control condition (blinking). Shown are a system in red identified from a seed in PSTS (MTN5, PSTS, Intraparietal sulcus, frontal eye fields, STG/STS, supramarginal gyrus, and middle frontal gyrus) and a system in blue identified from a fusiform seed (fusiform gyrus, STG/STS, and middle frontal gyrus) with the overlap of the two systems shown in green (superior temporal and middle frontal gyri). Figure 2, top panel with permission from Nummenmaa et al. (2010). Open Acess article. social attention mechanisms allow for prioritizing input and comprehending within a social context. This overlap between gaze/gesture processing and the more conceptual aspects of social cognition allows for the hypothesis that abnormal activity within regions that show activity related to visual (multimodal) gesture processing could also automatically confer erroneous information regarding the focus of social attention. Patients with delusions of reference often feel as though they are being watched. Those with persecutory delusions often feel as though they are being followed or watched and hence are the center of attention for some shadowy group of individuals. The abnormal computation of social attention could result in these delusions, as well as in social cognitive deficits and abnormal social/facial reactivity (as in flat affect and social inattentiveness). Schizophrenic subjects have been shown in a number of studies to have abnormal volitional saccades (e.g., Manoach et al., 2002) however recent studies indicate that this abnormality may be linked to cingulate cortex (Manoach et al., 2007; Tu et al., 2010).

\section{SALIENCY AND THE INTRAPARIETAL SULCUS OR IPS}

Schizophrenia has been hypothesized to be a result of abnormal motivational salience detection or computation (Kapur, 2003; Roiser et al., 2009; Walter et al., 2010). The computation of prediction error is thought by many investigators to be related to dopamine and the ventral striatal system with the differential valence of stimuli being conveyed by the orbitofrontal and anterior insula cortices (Jensen et al., 2007). However, within the IPS there are modules for the computation of salience. The IPS borders the inferior parietal cortex and receives input from the systems discussed in this paper. The IPS is involved in directing eye gaze as well as saliency detection, especially within the lateral intraparietal region (LIP). The LIP is thought to contain a saliency map (for all types of salience) that is used to determine the moment to moment focus of attention (Gottlieb, 2007). This map is constructed dynamically and modulated by behavioral context, goals and memory and is independent of hedonic value (Thompson and Bichot, 2005; Klein et al., 2008). Neurons in the macaque LIP were found to be associated with gaze following and showed predictive and "mirror" activity to gaze (Shepherd et al., 2009). The gaze mirror neurons were active both when the subject looked in the preferred direction of the neuron but also when an observed monkey looked in that direction, regardless of the task. The latencies of the neurons matched gaze following behavior. Another set of neurons encoded saliency within the task constraints. The LIP is connected to the perirhinal and parahippocampal regions (reviewed in Blatt et al., 1990; Gottlieb, 2007). Hence, aberrant salience computation or detection could be conferred by abnormal activity in the intraparietal region in schizophrenia due to abnormal input from the TPJ/PSTS regions.

\section{THEORY OF MIND AND THE TPJ}

The perception of others also involves the ability to understand and represent others mental states. Theory of mind is the ability to attribute and represent other's thoughts, desires, beliefs, and intentions (Saxe and Wexler, 2005; Decety and Grezes, 2006; Ochsner, 2008). Subjects can predict the goals of perceived actions and read or surmise the intentions of a person who is acting 
(Saxe and Wexler, 2005). Recent evidence shows that the TPJ is the core neural substrate for this function. Schizophrenic individuals are deficient in social and theory of mind processing (Sarfati et al., 1997, 1999; Pickup and Frith, 2001; Brunet et al., 2003a,b; Bora et al., 2009) and show abnormal activity during tasks which require mental state attribution (e.g., Andreasen et al., 2008; see Brunet-Gouet and Decety, 2006). Schizophrenic performance was similar to that of subjects with high functioning autism on a battery of social cognitive tasks (Couture et al., 2010).

Because of a consistent profile of activation in neuroimaging studies of social perception, the right TPJ has been designated by some investigators as "the social brain area" (Decety and Grezes, 2006). Activation in the right TPJ has been found to be specific to conditions that require "thinking about thoughts" relative to thinking about other socially relevant information (Saxe and Wexler, 2005). Right TPJ activity is selective to theory of mind and not to attention, memory demands, or expectations (Saxe and Wexler, 2005; Scholz et al., 2009; Young et al., 2010); see Figure 9. Other areas such as the Left TPJ, posterior cingulate and medial prefrontal cortex did not show such a selective response profile (Saxe and Wexler, 2005). Humans with lesions of the anterior cingulate or medial prefrontal cortex have not been found to be impaired in tasks measuring theory of mind (Bach et al., 2000; Bird et al., 2004; Baird et al., 2006). Patients with damage to the right TPJ have not been tested in these tasks, but damage to the left TPJ does result in an impairment of theory of mind (Samson et al., 2004; see Saxe and Wexler, 2005; Saxe and Wexler, discussion section for a review). Saxe and Wexler (2005) postulate that the left TPJ may play a role in processing more enduring socially relevant traits, while the right TPJ plays a role in the attribution of short lived or transitive mental states (emotions and situation specific thoughts). Abnormal activity in TPJ theory of mind regions could interfere with normal social cognitive function in schizophrenia. Above I described how neurons that are used to perceive dynamic gestures are tuned to "predict" or tuned

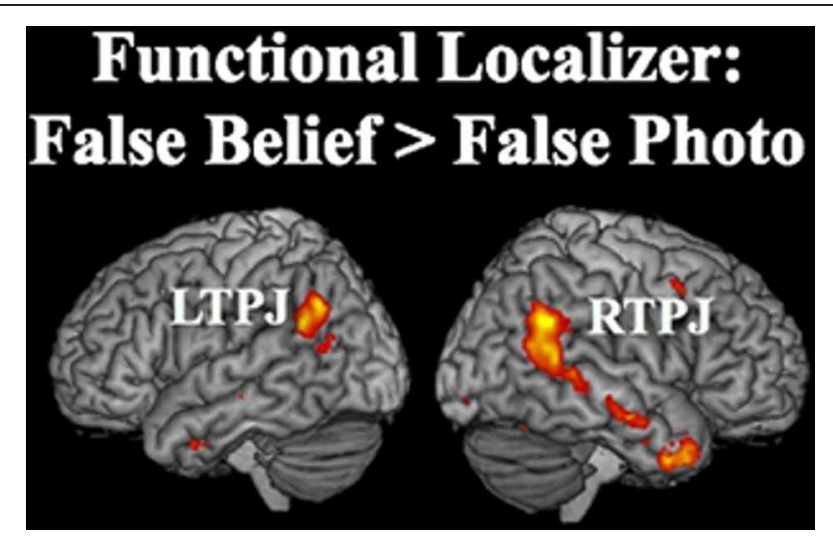

FIGURE 9 | Figure from Young et al. (2010)-Figure 3 from their paper-upper half. Theory of mind activation in the TPJ. TPJ regions where the $\mathrm{fMRI}$ activation was higher for stories about mental representations (e.g., false beliefs) than stories about physical representations such as false photographs. Reprinted with permission from Figure 3: Young et al. (2010). Copyright (C) 2010 Elsevier Ltd. All rights reserved. to detect future gesture sequences. Interference with this automatic predictive computation would be predicted to effect theory of mind functioning. The adjacency of regions subserving social attention, social emotional gesture perception, and theory of mind allows for hypothesized links between schizophrenic symptoms having to do with the abnormal social perception and social responding to theory of mind deficits. Schizophrenic delusions sometimes include the belief that they can read others' thoughts and also that others can hear their thoughts. These symptoms may also stem from the dysfunction of the theory of mind regions (e.g., lead to a feeling of mindreading).

\section{LANGUAGE AND TPJ FUNCTION}

For the sake of brevity, the role of the TPJ in language related symptoms will be described only briefly in this manuscript, although they are of central importance to the syndrome; see Ditman and Kuperberg (2010) for a recent review. The arguments put forth by Redcay (2008) for the PSTS being involved in autism are also germane to schizophrenia. In development we perceive gestures in others (e.g., eye gaze, voice, emotional gestures) and at the same time we receive information from self-made gestures (e.g., visual-spatial perspective, somatosensory, and vestibular information). Redcay (2008) reviews evidence that the perception of gestures in others that is experienced along with our own gestures and feelings may form the scaffolding on which the higher order multimodal perception of self, social attention, intention, agency and language are based (Redcay, 2008). This argument is aligned with much of the evidence reviewed in this manuscript (e.g., body swapping is caused by perturbations in visual perspective and touch). Eye gaze and other gestures experienced within the context of joint or social attention have been proposed to form part of the basis for language learning; eye gaze and joint attention are dependant on TPJ processing (see Redcay, 2008; Redcay et al., 2010). As mentioned above, audiovisual speech representation covers a large portion of the territory of the PSTS, including superior temporal and middle/inferior temporal regions in the posterior temporal lobe (Calvert and Campbell, 2003; Wright et al., 2003; Lotze et al., 2006; see Figure 1 in Wible et al., 2009b). A large portion of the TPJ (bilaterally) is also preferentially involved in narrative comprehension when compared to word or even sentence comprehension (see Figure 10 below from

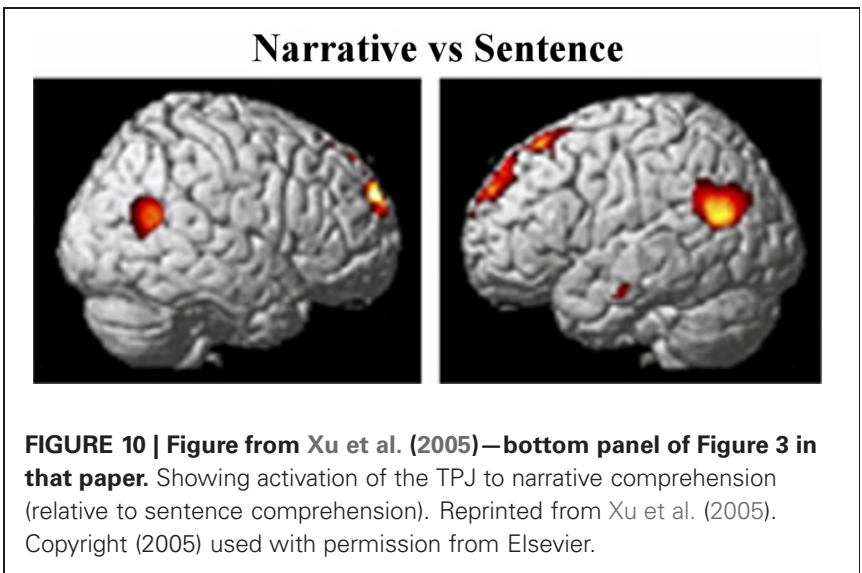


Redcay (2008); originally from Xu et al. (2005)—bottom panel of their Figure 3). Schizophrenic subjects are deficient in generating or building linguistic context. They are not able to construct coherence links across sentences to build-up overall global context during early phases of discourse comprehension (Ditman and Kuperberg, 2010). A careful analysis of the deficits and lesion sites in aphasia patients showed that when other confounding deficits were excluded, single word semantic processing deficits were found to be associated with the left posterior temporal and inferior parietal regions (Hart and Gordon, 1990). Hence the TPJ region is also involved in semantic comprehension (perhaps using similar computational and processing structures as are used for social perception).

The role of the TPJ/PSTS in audiovisual language, narrative comprehension and semantic representation may be linked to aspects of thought disorder and to concreteness seen in schizophrenia (Wible et al., 2009b). Auditory hallucinations may result from over-activation of PSTS audio-visual speech representations which would result in hearing a voice or voices and also the feeling of a presence or another speaking. This activation of audiovisual speech gestures may also provide feedback to activate more primary auditory regions augmenting the signal further and increasing attention to the "voices." Levels of auditory verbal hallucinations showed correlations with volumetric measures of the superior temporal region and with diffusion tensor imaging measures of white matter in tracts connecting posterior temporal and inferior parietal regions (Shenton et al., 2001; Hubl et al., 2004). Auditory hallucinations were linked to fMRI activity in inferior parietal and PSTS regions in a study of a large consortium study of schizophrenia (Wible et al., 2009a) as well as other studies, including a study examining a single hallucinating subject with fMRI (e.g., Lennox et al., 1999). Previous studies from our laboratory also found that levels of thought disorder and auditory hallucinations were associated with activity in the inferior parietal and PSTS regions in chronic schizophrenic subjects (Han et al., 2007; Hashimoto et al., 2010).

\section{HUMAN FUNCTIONAL IMAGING OF THE TPJ: BOTTOM UP ATTENTION, RECOLLECTIVE SUCCESS, WORKING MEMORY, SELF PROJECTION THROUGH TIME AND SPACE, AND A CORTICAL HUB THAT IS ACTIVE DURING TASK AND RESTING STATES}

Bottom up or reflexive attention and episodic retrieval have both been linked to inferior parietal/TPJ regions as shown by a recent review (Hutchinson et al., 2009). The TPJ was recently found to be a cortical hub and to be active both in rest and task states (Buckner et al., 2009). Note that this is different than the previous theoretical construct of a "default mode" network. Cortical hubs were also found in the posterior cingulate, and medial/lateral prefrontal cortices. It was hypothesized that regions active in the resting state are involved in "constructing self-relevant mental simulations that are exploited by a wide range of functions including remembering, thinking about the future, and inferring the perspectives and thoughts of other people" (Quote from Buckner et al., 2008). In that paper, schizophrenia was conceptualized as the loss of a strong boundary between perception from imagined and real scenarios, including the boundary between self and other perception. That manuscript also reviews the extensive evidence for abnormal default mode activity in schizophrenia. The (right) TPJ has also been hypothesized to be involved in self projection not only through space, but through time (Arzy et al., 2011). The aberrant perception of time and space in schizotypal personality disorder was found to be positively correlated with the duration of activation in the right TPJ and right occipito-temporal cortex (as well as the left anterior temporal regions; Arzy et al., 2011). Arzy et al. (2011) conceptualize some aspects of the schizophrenia spectrum syndrome as aberrant self projection through both time and space and the inability to bind together experienced life events into a cohesive whole; this autonoetic awareness forms part of the self-representation.

\section{PRODROMAL SYMPTOMS AND THE TPJ}

The phenomenology of the prodromal phase of schizophrenia has been linked to inferior parietal dysfunction. Torrey (2007) recently described the convergence between early symptoms and neurological signs of inferior parietal damage. He noted that prodromal patients frequently present with disorders of body image. Here I note some examples of prodromal symptoms that may reflect the abnormal activation of PSTS/inferior parietal multimodal representations. The quotes shown below are from published accounts (McGhie and Chapman, 1961; Torrey, 2007). Descriptions of prodromal symptoms are grouped into several categories as follows: (1) Symptoms reflecting the abnormal capture of bottom up attention: "Everything seems to grip my attention although I am not particularly interested in anything." "Everything that is going on seems to be picked up by me..." "Noises all seem to be louder." "Colors seem to be brighter now." (2) Symptoms reflecting the over-activation of biological motion representations by environmental stimuli: "Everything looked vibrant, especially red; ... all sorts of objects-chairs, buildings, obstacles-took on a life of their own; they seemed to make threatening gestures, to have an animistic outlook....I feel that everything is coming toward me." (3) Symptoms reflecting the inability to integrate sensory data into a coherent pattern as is seen in patients with lesions of TPJ (Coslett and Lie, 2008): "I have to put things together in my head. If I look at my watch I see the watchstrap, watch, face, hands and so on, then I have got to put them together to get it into one piece." "Everything is in bits. You put the picture up bit by bit in your head." (4) Symptoms reflecting deficient narrative comprehension: "I can concentrate quite well on what people are saying if they talk simply. It is when they go into long sentences that I lose the meanings. The subjective experience in schizophrenia was described in a recent paper by a researcher who has the disease (Chadwick, 2007). He too described an inability of the normally automatic and unconscious integration of sensory data. "...I would have to grasp situations by apprehending their parts rather than grasping them intuitively and holistically."

\section{RELATIONSHIP TO OTHER THEORETICAL VIEWS}

This framework is at least partially based on theoretical views of schizophrenia that posit specific neurotransmitter related abnormalities such as NMDA processing (Coyle, 2006; Butler et al., 2009; Javitt, 2009). The views here are consistent with 
the supposition that the magnocellular system is differentially affected by abnormal NMDA processing in schizophrenia (Javitt, 2009). It is assumed that the TPJ is especially vulnerable to processing abnormalities because of its relationship to hippocampal processing which is heavily dependant on NMDA/GABA and because it is part of the magnocellular visual processing stream. The framework is partially consistent with some views that emphasize saliency, perceptual/emotional bias and other putative psychological difficulties (e.g., Frith et al., 1992; Freeman et al., 2002; Kapur, 2003; Holt et al., 2006) and may provide a way to further conceptualize and test these alternatives. Our focus on social cognition in schizophrenia is similar to the focus of several other groups and is based on their experimental work (Carter, 2006; Hoffman, 2007; Ochsner, 2008; Carter et al., 2009; Fletcher and Frith, 2009). Our views are also partially consistent with those positing abnormal or deficient corollary discharge signals (Whitford et al., 2012). A current version of this theory links abnormal corollary discharge to abnormal salience computation in schizophrenia and to dopamine. I posit that abnormal feedback from self-initiated actions could be one component of the syndrome, but my view focuses on feedback from (possibly M1) to inferior parietal cortex, not from DLPFC to auditory cortex. A focus on the hippocampus is also found in a rodent model of schizophrenia in which a neonatal ventral hippocampal lesion is made and leads to changes in interneurons in the prefrontal cortex. This neonatal lesion affects dopamine-resulting in abnormal prefrontal dopamine-glutamate interactions that emerge after puberty (Tseng et al., 2007). This theory differs from ours in terms of the focus on dopamine and frontal lobe (see discussion below). In another animal (rodent) model of schizophrenia, either the abnormal function or loss of fast-spiking interneurons that contain the calcium-binding protein parvalbumin (PV) is thought to produce gamma band synchrony deficits resulting in schizophrenia (e.g., Woo et al., 2010; Powell et al., 2012). Changes in PV interneurons can occur in adolescence (in animal models) subsequent to early oxidative stress. Developmental interventions such as the application of an NMDA receptor antagonist or social isolation in an early postnatal period has been shown to produce changes in PV interneurons in adolescence in these animal models and these interneurons are thought to be involved in the generation of gamma oscillations (Woo et al., 2010; Powell et al., 2012). The current framework does propose a (more localized) role for gamma oscillations in schizophrenia. However, the current framework postulates a special role for the TPJ, not widespread brain abnormalities, in producing symptoms. Note that widespread gamma abnormalities have also been found in tinnitus, Alzheimer's disease, autism, Tourette's syndrome, bipolar disorder, attention deficit disorder, and traumatic brain injury (Schlee et al., 2009; Woo et al., 2010).

Hence, although some components are overlapping with other theories of schizophrenia, our focus and conceptualization of the syndrome is significantly different from these views in many respects. Perhaps the most important differences have to do with the identification of psychological functions and brain regions that are relevant to understanding schizophrenia. A major focus for most schizophrenia research has been on DLPFC and medial prefrontal regions in working memory, cognitive control, conflict detection and possibly social cognition (Manoach, 2003; Goldman-Rakic et al., 2004; Carter and van Veen, 2007; Tan et al., 2007; Kerns et al., 2008; Polli et al., 2008). Several findings within the field of cognitive neuroscience within the last several years impact upon some of the more prevalent views of prefrontal function and the relationship between frontal dysfunction and schizophrenia; these views may need to be updated to some extent to reflect new findings (Wible, 2012). Theory of mind was previously thought to depend on the anterior cingulate or paracingulate region, but recent lesion data have challenged this view (Bird et al., 2004; Baird et al., 2006; Wible, 2012). However, PSTS damage does cause theory of mind deficits (Samson et al., 2004). Anterior cingulate lesions also do not produce deficiencies in cognitive control or indices of prediction error as measured by several types of tasks including performance of the Stroop and go-no go tasks (e.g., Fellows and Farah, 2005; Baird et al., 2006; Wible, 2012). Although there is still much controversy regarding the role of the prefrontal cortex in memory, the often hypothesized association between working memory maintenance, DLPFC cortex, and schizophrenia may have to be revised (for example see Ghent et al., 1962; Petrides et al., 1993; Postle, 2006; Buchsbaum and D'Esposito, 2008). The lack of relationship between human prefrontal damage and working memory (maintenance/rehearsal) impairment is illustrated by the following quote from D'Esposito and Postle (1999): "We found that none of the eleven studies of forward verbal and spatial span in patients with prefrontal cortical lesions that we reviewed (reflecting the performance of 166 individual patients) demonstrated a statistically significant deficit relative to normal controls." That review goes on to state that lesions in the inferior parietal cortex are associated with disrupted working memory. This lack of association between frontal cortex damage and working memory impairment was also found years before by Frisk and Milner (1990) who used patients with frontal cortex damage to test Baddeley's theory that damage to the frontal cortex would be associated with an overall reduction in working memory capacity. They did not observe a relationship between frontal lobe damage and working memory performance on any of their measures. Recent theories posit that frontostriatal circuitry may be involved in the selection of appropriate motor responses based on working memory content (e.g., Curtis and D'Esposito, 2003; Manoach et al., 2003). Hence I hypothesize that the working memory deficits in schizophrenia stem primarily from abnormal TPJ activity since the TPJ shows activity related to working memory and lesions of this region produce working memory deficits (reviewed in Wible et al., 2009b). A recent study from our laboratory provides evidence for a link between abnormal activity in TPJ working memory circuits and symptoms (Hashimoto et al., 2010).

\section{SUMMARY AND SYNTHESIS}

In summary, it is hypothesized that over-activation of the TPJ region is the core processing abnormality in schizophrenia and results in the phenomenology of the syndrome; see Table $\mathbf{1}$ for examples. This over-activation or prolonged activation (Arzy et al., 2006, 2011) could stem from NMDA/GABA abnormalities and over-activation of the hippocampus perhaps in conjunction with abnormal processing in the magnocellular stream (Coyle, 
2006; Woo et al., 2008; Javitt, 2009). TPJ activity is highly correlated with hippocampal system activity. The hippocampus is highly prone to excitotoxic damage from many sources (also prone to epilepsy). Over-activation from the hippocampus could reach a peak around adolescence. The CA1 layer of the hippocampus undergoes myelination at that time and sex hormones would be influencing hippocampal activity. The TPJ also undergoes myelination and development in this late stage. The coincidence of neural development and sex hormone activity might act to produce aberrant activity in this circuit that results in symptoms. Fast spiking PV interneurons have been implicated in the pathogenesis of both schizophrenia and epilepsy (Li et al., 2011). Schizophrenic abnormalities may be caused by a chronic low level over-excitation that is either initiated or exacerbated during adolescence. Episodes of prolonged or heightened activity would be expected to ultimately change the processing of both the hippocampus and TPJ/PSTS and to ultimately lead to excitotoxic tissue loss over time. These abnormalities would be expected over time to extend to primary efferent sites (especially ventral prefrontal cortex) and then other efferent areas. Feedback activation from the TPJ to primary areas (especially auditory cortex) would also be expected to produce abnormalities in the primary regions (e.g., Kasai et al., 2003).

The results of meta-analyses and reviews led to the hypothesis that the TPJ was involved in dynamic social interaction, a view that has been confirmed in a recent human fMRI study of dynamic live face to face interaction within the scanner (Decety and Lamm, 2007; Redcay, 2008; Wible et al., 2009b; Redcay et al., 2010; Wible, 2012). This region is involved in dynamic gesture and person perception that is multimodal (predominantly using the auditory, visual, and tactile modalities). Auditory and visual hallucinations of people/voices predominate in schizophrenia, followed by tactile hallucinations. The dynamic social perception subserved by this region is also based on the gamma synchronization of more primary cortical regions. This dynamic gamma synchronization may act as an attentional mechanism to augment incoming information in relevant perceptual channels. This neural augmentation could also result in hallucinations because of increased activity in primary areas (especially for auditory, visual, and somatosensory cortices). The TPJ may serve as a convergence point for the coordinated activation of information from several domains in order to form the contextual gestalt perception of socially dynamic gestures and speech. The dominant role of the TPJ in narrative comprehension and working memory supports the view that one aspect of the functionality of this region is in the automatic coordination of the activation/retrieval of distributed cortical modules and the coordination of information used to support perception and action under complex naturalistic conditions. Consistent with this supposition is the fact that posterior parietal damage (the posterior portion of the inferior parietal lobe) can cause the breakdown of the normally automatic perception of simultaneous perceptual attributes (Coslett and Lie, 2008).

Since neural activity in this region corresponds to social perception and joint attention, then over-activation of this region could result in the erroneous perception of being within a dynamic social situation and would be predicted to have widespread consequences for many domains including social perception, reactivity, and attention. Over-activation of this system could cause phenomenon from the conscious perception of dynamic social percepts or entities (persons), scenes, or audiovisual speech representations (voices) to the unconscious feeling of being watched or of being in the center of a social situation (representations of eye gaze, social attention). Inherent in the perceptual processing of dynamic gestures is a tuning or coding of social prediction. The processing of gestalt or more integrative or contextual aspects of reality would be expected to break down. The breakdown of predictive coding would result in slowing or abnormal expectation, perception, and reaction within social contexts. It might also interfere with keeping track of other's (or self) actions. Information about agency and intention is also inherent in the code that underlies the perception of dynamic gestures. Abnormal activation of dynamic gesture representations would also produce an automatic or obligatory accompanying perception of agency and intention. Symptoms such as persecutory delusions and delusions of jealousy may be reframed as hallucinations of agency and intention. The over-activation of PSTS and inferior parietal regions would be expected to cause abnormal activation of saliency maps in the intraparietal sulcus leading to abnormal saliency detection. The overlap between representational systems and regions that are used in the perception of the self and in the perception of the social other allows us to infer that abnormal activity related to dynamic gesture perception would impact the self-representation and result in disturbances of self-perception (e.g., somatic hallucinations, somatic delusions, delusions of grandeur, delusions of control). Abnormal activation of the neural elements that are used in self representation can also produce the sense of a presence of another or others (due to a form of heautoscopy). This sensation could underlie many of the symptoms (e.g., delusions of reference; delusions of persecution) and would also interfere with agency judgments. The overlap between agency processing and dynamic gesture perception allows us to infer that abnormal activity related to dynamic gesture perception would impact agency processing and could also result in the misattribution of agency (e.g., delusions of control, thought broadcasting, thought insertion). Although the multimodal representations in the STS of monkey and humans are used in gesture perception, the neurons in this region are biased to detect threat. The detection of threat may be linked in evolution to reproductive competitiveness as mate competition would be a significant source of social threat. This might explain the empirical findings that in humans and monkeys this gesture perception system is tuned to detect threat as well as being active under conditions of sexual competition (Perrett et al., 1985a; Oram and Perrett, 1994; Wheaton et al., 2001; Puce and Perrett, 2003; Rilling et al., 2004; Takahashi et al., 2006). Over-activation of these representations would be expected to result in a bias for perceiving social threat and reproductive competition resulting in negative perceptual biases (e.g., delusions of persecution and jealousy; delusions of reference). Affect perception involves dynamic gestures of the face and body. Human lesion studies have shown that the recognition of affect from faces and prosody depends on inferior parietal (supramarginal), superior temporal, somatosensory, and motor regions that are used to produce emotional and 
prosodic reactions. Hence, abnormal activity in the system for perceiving dynamic gestures would be expected to interfere with emotional reactivity in the face and voice resulting in flat affect and unreactivity/affective nonresponsiveness or abnormal reactivity. The TPJ/PSTS also plays a primary role in the perception of gaze and joint attention; abnormal activity could result in several symptoms (e.g., attention deficits, facial unreactivity, and delusions of reference-feeling of being watched). The dominant role of the (right) TPJ in theory of mind processing allows us to infer that aberrant activation of this region would interfere with theory of mind processing resulting in the abnormal perception of intentions, abnormal social interaction and in errors of social inference.

The framework described here provides a basis for understanding how specific aspects of the schizophrenic syndrome are related. These relationships are based on representational properties that are found at the level of single unit recording in monkeys and that are consistent with the results of lesion, brain stimulation, and functional imaging studies in humans. Within this framework, the cognitive deficiencies and positive and negative symptoms are linked and are tied to the representational structure and functional architecture that is evident in this posterior system that is used in social perception and interaction. Abnormal activity within this system would be expected to affect efferent targets in the frontal lobe. However, it is hypothesized that the core abnormalities stem from the over-activation or prolonged activation of posterior regions.

\section{EVALUATION OF THE FRAMEWORK AND CURRENT EVIDENCE}

It is important to note that the TPJ is among the most anatomically variable regions in the human brain, and hence morphometric abnormalities may be difficult to detect. Because of the role of the TPJ in self-representation, other representation, thought and language, functional abnormalities may also be difficult to detect with current (subtractive) functional imaging techniques. These functions are all present or active in the resting state. It is hypothesized that this system should show slightly elevated activity interposed with epochs of hyper-activation that correspond to the abnormal qualia (hallucinations and delusions) and responsive deficiencies (negative symptoms) seen in schizophrenia. Baseline activity, not task-related activity should be elevated. This necessitates that task related activity in this region (which is computed as a function of the baseline) will be affected (decreased). Experiments using subtractive designs may subtract out the functionality of the TPJ and hippocampus because they are active in rest and task states. However, the data from our previously published studies show evidence for our hypotheses (e.g., Kubicki et al., 2003; Han et al., 2007; Hashimoto et al., 2010; Wible et al., 2009a). The Hashimoto et al. (2010) study found that levels of delusions were correlated with activity in the PSTS (not a mid-STS region); this activity subserved rehearsal in a working memory task. This study showed a direct link between auditory hallucinations, delusions, and working memory activity. In addition, there have been at least six published reports showing that TMS application to the TPJ in schizophrenic subjects reduces schizophrenic symptoms (e.g., Lee et al., 2005; Jardri et al., 2007).
Hippocampal over-activation in schizophrenia has been found to be independent of frontal abnormalities (Ragland et al., 2005). A meta-analysis of schizophrenia morphometric studies showed the most evidence for reductions in (left) superior temporal and hippocampal regions (Honea et al., 2005; see also Gur et al., 2000; Eliez et al., 2001). Studies using large numbers of subjects to examine schizophrenic morphometric measures have recently been published. One study used large numbers of schizophrenia spectrum subjects compared to siblings and normal controlssee Figure 11 (Honea et al., 2008). Another study combined data from two consortiums, the FBIRN and Mind Clinical Imaging Consortium or MCIC to examine brain volume in schizophrenic (and schizoaffective) and control subjects—see Figure 12. These data comprise subjects from nine sites across the country (our laboratory also contributed data to this dataset). The TPJ, especially in the right hemisphere, was implicated in both studies even though patients with affective components were included.

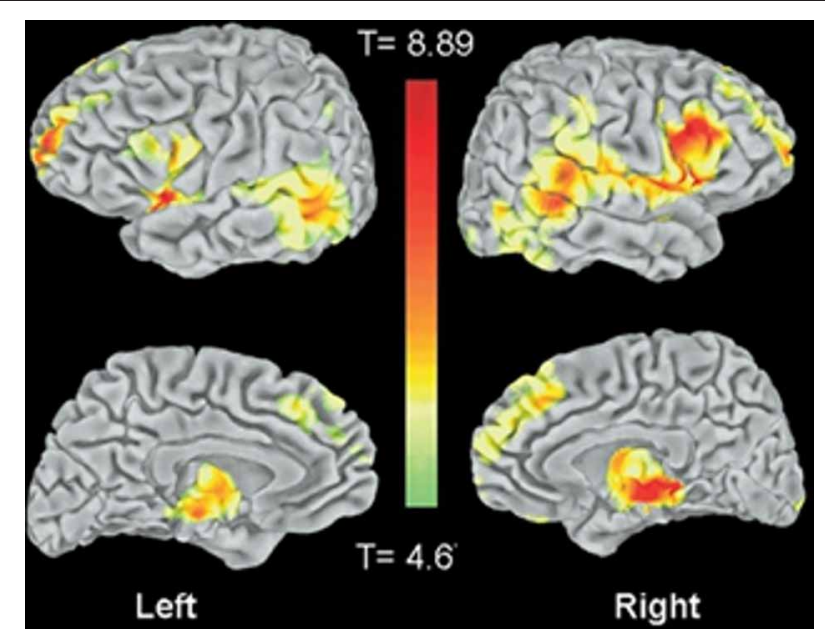

FIGURE 11 | From Honea et al. (2008) showing data from a large morphometric study using 169 patients with schizophrenia-spectrum disorders and 212 control subjects Statistical maps of the entire brain showing gray matter volume reductions in schizophrenics versus control subjects. Figure 1 panel A reprinted with permission from Honea et al. (2008). (c) 2008 Society of Biological Psychiatry.

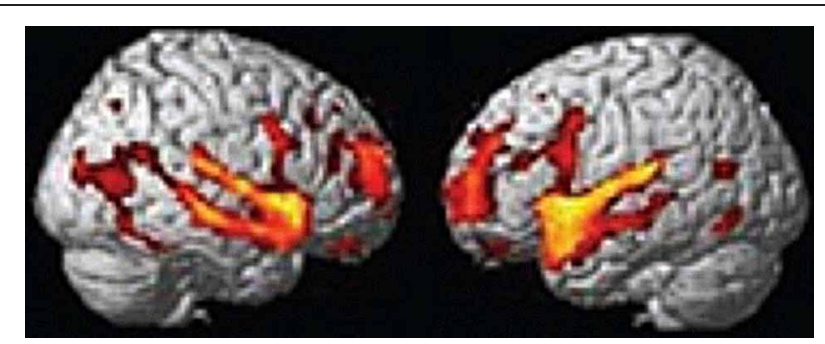

FIGURE 12 | From Segall et al. (2009) a large morphometric study of patients with schizophrenia or schizoaffective disorder and controls based on data from two consortiums with sites across the country (FBIRN and MCIC). Left panel shows right hemisphere and Right panel shows left hemisphere. The combined FBIRN and $\mathrm{MCIC}$ data set consists of 237 schizophrenic and 266 control subjects. Reprint of Figure 1, panel C with permission from the author from Segall et al. (2009). 
Hence, the results of volume analysis of these large datasets match the predictions put forth here [as seen in the figures throughout the paper and in Wible et al. (2009b)] and lend support to the current framework.

More targeted investigations of these regions using naturalistic dynamic stimuli in functional imaging experiments should yield insight into the function of this system in schizophrenia. Episodic over-activation of the hippocampus and TPJ should be associated with the onset and psychotic episodes of schizophrenia and may even be used to predict conversion in high risk individuals. As described above, activity in affected regions would be expected to show at least a modest increased baseline activity even between active episodes or symptoms such as hallucinations and delusions. This system is not fully understood, although rapid progress is being made. As the components and characteristics of the system become clear so should its role in producing psychosis. The framework allows for the linking of more molecular and genetic abnormalities (e.g., in hippocampus) to systems level cognitive neuroscience (a domain in which symptoms and behavior can be understood). A framework such as this should lead to the development of better animal models of

\section{REFERENCES}

Adolphs, R., Damasio, H., and Tranel, D. (2002). Neural systems for recognition of emotional prosody: a 3-D lesion study. Emotion 2, 23-51.

Adolphs, R., Damasio, H., Tranel, D., Cooper, G., and Damasio, A. R. (2000). A role for somatosensory cortices in the visual recognition of emotion as revealed by three-dimensional lesion mapping. J. Neurosci. 20, 2683-2690.

Adolphs, R., Damasio, H., Tranel, D., and Damasio, A. R. (1996). Cortical systems for the recognition of emotion in facial expressions. J. Neurosci. 16, 7678-7687.

Akiyama, T., Kato, M., Muramatsu, T., Saito, F., Umeda, S., and Kashima, H. (2006). Gaze but not arrows: a dissociative impairment after right superior temporal gyrus damage. Neuropsychologia 44, 1804-1810.

Allison, T., Puce, A., and McCarthy, G. (2000). Social perception from visual cues: role of the STS region. Trends Cogn. Sci. 4, 267-278.

Altschuler, E. L., and Ramachandran, V. S. (2007). A simple method to stand outside oneself. Perception 36, 632-634.

Andreasen, N. C. (1981). Scale for the Assessment of Negative Symptoms (SANS). Iowa City, IA: University of Iowa College of Medicine.

Andreasen, N. C. (1984). Scale for the Assessment of Positive Symptoms (SAPS). Iowa City, IA: University of Iowa College of Medicine.

Andreasen, N. C. (1999). A unitary model of schizophrenia: Bleuler's "fragmented phrene" Psychiatry 56, 781-787.

Andreasen, N. C., Calarge, C. A., and O'Leary, D. S. (2008). Theory of mind and schizophrenia: a positron emission tomography study of medication-free patients. Schizophr. Bull. 34, 708-719.

Andersen, R. A., Snyder, L. H., Bradley, D. C., and Xing, J. (1997). Multimodal representation of space in the posterior parietal cortex and its use in planning movements. Annu. Rev. Neurosci. 20, 303-330.

Arzy, S., Mohr, C., Molnar-Szakacs, I., and Blanke, O. (2011). Schizotypal perceptual aberrations of time: correlation between score, behavior and brain activity. PLOS ONE 6:e16154. doi: 10.1371/journal. pone. 0016154

Arzy, S., Seeck, M., Ortigue, S., Spinelli, L., and Blanke, O. (2006). Induction of an illusory shadow person. Nature 443, 287.

Astafiev, S. V., Stanley, C. M., Shulman, G. L., and Corbetta, M. (2004). Extrastriate body area in human occipital cortex responds to the performance of motor actions. Nat. Neurosci. 7, 542-548.

Atkinson, A. P., and Adolphs, A. (2005). "Visual emotion perception: mechanisms and processes," in Emotion and Consciousness, eds L. F. Barrett, P. M. Niedenthal, and P. Winkielman (New York, NY: Guilford Press), 150-182.

Atkinson, A. P., Heberlein, A. S., and Adolphs, R. (2007). Spared ability to recognise fear from static and moving whole-body as schizencephaly. Arch. Gen.

psychiatric disease. Elements of this framework may be applicable to other diseases such as autism (tonic overactivation from the hippocampus from an early age interfering with the formation of self, other and language representation), PTSD (hippocampus, stress, and reactivation of threatening action related percepts and memories), paranoid personality disorder (a milder form of persecutory delusions) and depression in affective psychosis (symptoms similar to Cotard's Syndrome- see Wible et al., 2009b).

\section{ACKNOWLEDGMENTS}

This work was supported by an NIMH grant: 1 R01 MH067080$01 \mathrm{~A} 2$ and by the Harvard Neuro-Discovery Center (formally HCNR). Funded also by the Biomedical Informatics Research Network (U24RR021992); National Institute of Mental Health. Support was also received from NIMH 1R01 MH52807, NIH MH40799, a Veteran's Administration (VA) Merit award, a VA Research Enhancement Award Program (REAP), and a VA Medical Center of Excellence Award (principal investigator for these grants: Robert W. McCarley). The author would like to thank Israel Molina for assembling the reference section.

cues following bilateral amygdala damage. Neuropsychologia 45, 2772-2782.

Ayhan, Y., Abazyan, B., Nomura, J., Kim, R., Ladenheim, B., Krasnova, I. N., Sawa, A., Margolis, R. L., Cadet, J. L., Mori, S., Vogel, M. W., Ross, C. A., and Pletnikov, M. V. (2011). Differential effects of prenatal and postnatal expressions of mutant human DISC1 on neurobehavioral phenotypes in transgenic mice: evidence for neurodevelopmental origin of major psychiatric disorders. Mol. Psychiatry 16, 293-306.

Bach, L. J., Happe, F., Fleminger, S., and Powell, J. (2000). Theory of mind: independence of executive function and the role of the frontal cortex in acquired brain injury. $\operatorname{Cog} n$. Neuropsychiatry 5, 175-192.

Baird, A., Dewar, B. K., Critchley, H., Gilbert, S. J., Dolan, R. J., and Cipolotti, L. (2006). Cognitive functioning after medial frontal lobe damage including the anterior cingulate cortex: a preliminary investigation. Brain Cogn. 60, 166-175.

Baizer, J. S., Ungerleider, L. G., and Desimone, R. (1991). Organization of visual inputs to the inferior temporal and posterior parietal cortex in macaques. J. Neurosci. 11, 168-190.

Baron-Cohen, S., Wheelwright, S., and Jolliffe, T. (1997). Is there a "Language of the Eyes"? Evidence from normal adults, and adults with autism or Asperger syndrome. Vis. Cogn. 4, 311-331.
Barraclough, N. E., Xiao, D., Baker, C. I., Oram, M. W., and Perrett, D. I. (2005). Integration of visual and auditory information by superior temporal sulcus neurons responsive to the sight of actions. J. Cogn. Neurosci. 17, 377-391.

Barresi, J., and Moore, C. (1996). Intentional relations and social understanding. Behav. Brain Sci. 19, 107-122.

Beauchamp, M. S. (2005). Statistical criteria in fMRI studies of multisensory integration. Neuroinformatics 3, 93-113.

Beauchamp, M. S., Argall, B. D., Bodurka, J., Duyn, J. H., and Martin, A. (2004). Unraveling multisensory integration: patchy organization within human STS multisensory cortex. Nat. Neurosci. 7, 1190-1192.

Beauchamp, M. S., Yasar, N. E., Frye, R. E., and Ro, T. (2008). Touch, sound and vision in human superior temporal sulcus. Neuroimage 41, 1011-1020.

Benes, F. M. (1989). Myelination of cortical-hippocampal relays during late adolescence. Schizophr. Bull. 15, 585-593.

Benes, F. M. (1999). Evidence for altered trisynaptic circuitry in schizophrenic hippocampus. Biol. Psychiatry 46, 589-599.

Benes, F. M., Lim, B., Matzilevich, D., Walsh, J. P., Subburaju, S., and Minns, M. (2007). Regulation of the GABA cell phenotype in hippocampus of schizophrenics and bipolars. Proc. Natl. Acad. Sci. U.S.A. 104, 10164-10169. 
Berthier, M., and Starkstein, S. (1987). Acute atypical psychosis following a right hemisphere stroke. Acta Neurol. Belg. 87, 125-131.

Billino, J., Braun, D. I., Bohm, K. D., Bremmer, F., and Gegenfurtner, K. R. (2009). Cortical networks for motion processing: effects of focal brain lesions on perception of different motion types. Neuropsychologia 47, 2133-2144.

Bird, C. M., Castelli, F., Malik, O., Frith, U., and Husain, M. (2004). The impact of extensive medial frontal lobe damage on 'Theory of Mind' and cognition. Brain 127, 914-928.

Bisiach, E., and Vallar, G. (2000). "Unilateral neglect in humans," in Handbook of Neuropsychology, eds F. Boller, J. Grafman, and G. Rizzolatti (Amsterdam: Elsevier Science B-V), 459-502.

Blakemore, S. J., and Decety, J. (2001). From the perception of action to the understanding of intention. Nat. Rev. Neurosci. 2, 561-567.

Blakemore, S. J., Oakley, D. A., and Frith, C. D. (2003). Delusions of alien control in the normal brain. Neuropsychologia 41, 1058-1067.

Blanke, O., and Arzy, S. (2005). The out-of-body experience: disturbed self-processing at the temporoparietal junction. Neuroscientist 11, 16-24.

Blanke, O., Ortigue, S., Landis, T., and Seeck, M. (2002). Stimulating illusory own-body perceptions. Nature 419, 269-270.

Blatt, G. J., Andersen, R. A., and Stoner, G. R. (1990). Visual receptive field organization and corticocortical connections of the lateral intraparietal area (area LIP) in the macaque. J. Comp. Neurol. 299, 421-445.

Boddaert, N., Chabane, N., Gervais, H., Good, C. D., Bourgeois, M., Plumet, M. H., Barthélémy, C., Mouren, M. C., Artiges, E., Samson, Y., Brunelle, F., Frackowiak, R. S., Zilbovicius, M. (2004). Superior temporal sulcus anatomical abnormalities in childhood autism: a voxel-based morphometry MRI study. Neuroimage 23, 364-369.

Bogerts, B. (1997). The temporolimbic system theory of positive schizophrenic symptoms. Schizophr. Bull. 23, 423-435.

Bogerts, B., Meertz, E., and SchonfeldtBausch, R. (1985). Basal ganglia and limbic system pathology in schizophrenia. A morphometric study of brain volume and shrinkage. Arch. Gen. Psychiatry 42, 784-791.

Bora, E., Yucel, M., and Pantelis, C. (2009). Theory of mind impairment in schizophrenia: meta-analysis. Schizophr. Res. 109, 1-9.

Brandt, T., Bartenstein, P., Janek, A., and Dieterich, M. (1998). Reciprocal inhibitory visualvestibular interaction. Visual motion stimulation deactivates the parieto-insular vestibular cortex. Brain 121(Pt 9), 1749-1758.

Bremmer, F., Schlack, A., Shah, N. J., Zafiris, O., Kubischik, M. Hoffmann, K., Zilles, K., and Fink, G. R. (2001). Polymodal motion processing in posterior parietal and premotor cortex: a human fMRI study strongly implies equivalencies between humans and monkeys. Neuron 29, 287-296.

Brown, R., Colter, N., Corsellis, J. A., Crow, T. J., Frith, C. D., Jagoe, R., Johnstone, E. C., and Marsh, L. (1986). Postmortem evidence of structural brain changes in schizophrenia. Differences in brain weight, temporal horn area, and parahippocampal gyrus compared with affective disorder. Arch. Gen. Psychiatry 43, 36-42.

Bruce, C., Desimone, R., and Gross, C. G. (1981). Visual properties of neurons in a polysensory area in superior temporal sulcus of the macaque. J. Neurophysiol. 46, 369-384.

Brugger, P., Blanke, O., Regard, M., Bradford, D. T., and Landis, T. (2006). Polyopic heautoscopy: case report and review of the literature. Cortex 42, 666-74.

Brune, M., Abdel-Hamid, M., Sonntag, C., Lehmkamper, C., and Langdon, R. (2009). Linking social cognition with social interaction: nonverbal expressivity, social competence and "mentalising" in patients with schizophrenia spectrum disorders. Behav. Brain Funct. 5, 6.

Brunet, E., Sarfati, Y., and HardyBayle, M. C. (2003a). Reasoning about physical causality and other's intentions in schizophrenia. Cogn. Neuropsychiatry 8, 129-139.

Brunet, E., Sarfati, Y., Hardy-Bayle, M. C., and Decety, J. (2003b). Abnormalities of brain function during a nonverbal theory of mind task in schizophrenia. Neuropsychologia 41, 1574-1582.

Brunet-Gouet, E., and Decety, J. (2006). Social brain dysfunctions in schizophrenia: a review of neuroimaging studies. Psychiatry Res. $148,75-92$.

Buccino, G., Binkofski, F., Fink, G. R., Fadiga, L., Fogassi, L., Gallese, V., Seitz, R. J., Zilles, K., Rizzolatti, G., and Freund, H. J. (2001). Action observation activates premotor and parietal areas in a somatotopic manner: an fMRI study. Eur. J. Neurosci. 13, 400-404.

Buchsbaum, B. R., and D'Esposito, M (2008). The search for the phonological store: from loop to convolution. J. Cogn. Neurosci. 20, 762-778.

Buckner, R. L., Andrews-Hanna, J. R., and Schacter, D. L. (2008). The brain's default network: anatomy, function, and relevance to disease. Ann. N.Y. Acad. Sci. 1124, 1-38.

Buckner, R. L., Sepulcre, J., Talukdar, T., Krienen, F. M., Liu, H., Hedden, T., Andrews-Hanna, J. R., Sperling, R. A., and Johnson, K. A. (2009). Cortical hubs revealed by intrinsic functional connectivity: mapping, assessment of stability, and relation to Alzheimer's disease. J. Neurosci. 29, 1860-1873.

Butler, P. D., Abeles, I. Y., Weiskopf, N. G., Tambini, A., Jalbrzikowski, M., Legatt, M. E., Zemon, V., Loughead, J., Gur, R. C., and Javitt, D. C. (2009). Sensory contributions to impaired emotion processing in schizophrenia. Schizophr. Bull. 35 1095-1107.

Butler, P. D., Zemon, V., Schechter, I., Saperstein, A. M., Hoptman, M. J., Lim, K. O., Revheim, N. Silipo, G., and Javitt, D. C. (2005). Early-stage visual processing and cortical amplification deficits in schizophrenia. Arch. Gen. Psychiatry $62,495-504$.

Calvert, G. A. (2001). Crossmodal processing in the human brain: insights from functional neuroimaging studies. Cereb. Cortex 11 1110-1123.

Calvert, G. A., and Campbell, R. (2003) Reading speech from still and moving faces: the neural substrates of visible speech. J. Cogn. Neurosci. 15 57-70.

Carr, L., Iacoboni, M., Dubeau, M C., Mazziotta, J. C., and Lenzi, G. L. (2003). Neural mechanisms of empathy in humans: a relay from neural systems for imitation to limbic areas. Proc. Natl. Acad. Sci. U.S.A. 100, 5497-5502.

Carter, C. S. (2006). Re-conceptualizing schizophrenia as a disorder of $\operatorname{cog}$ nitive and emotional processing: a shot in the arm for translational research. Biol. Psychiatry 60 1169-1170.

Carter, C. S., Barch, D. M., Gur R., Pinkham, A., and Ochsner, K. (2009). CNTRICS final task selection: social cognitive and affective neuroscience-based measures. Schizophr. Bull. 35, 153-162.

Carter, C. S., and van Veen, V. (2007). Anterior cingulate cortex and conflict detection: an update of theory and data. Cogn. Affect. Behav. Neurosci. 7, 367-379.

Carter, E. J., and Pelphrey, K. A. (2008). Friend or foe? Brain systems involved in the perception of dynamic signals of menacing and friendly social approaches. Soc. Neurosci. 3, 151-163.

Chadwick, P. K. (2007). Peerprofessional first-person account: schizophrenia from the insidephenomenology and the integration of causes and meanings. Schizophr. Bull. 33, 166-173.

Chen, Y., Grossman, E. D., Bidwell, L. C., Yurgelun-Todd, D., Gruber, S. A., Levy, D. L., Nakayama, K., and Holzman, P. S. (2008). Differential activation patterns of occipital and prefrontal cortices during motion processing: evidence from normal and schizophrenic brains. Cogn. Affect. Behav. Neurosci. 8, 293-303.

Clower, D. M., West, R. A., Lynch, J. C., and Strick, P. L. (2001). The inferior parietal lobule is the target of output from the superior colliculus, hippocampus, and cerebellum. J. Neurosci. 21, 6283-6291.

Coltheart, M. (2007). Cognitive neuropsychiatry and delusional belief Q. J. Exp. Psychol. (Hove) 60, 1041-1062.

Corbetta, M., Patel, G., and Shulman, G. L. (2008). The reorienting system of the human brain: from environment to theory of mind. Neuron 58 306-324.

Corlett, P. R., Taylor, J. R., Wang, X. J., Fletcher, P. C., and Krystal, J. H. (2010). Toward a neurobiology of delusions. Prog. Neurobiol. 92, 345-369.

Corradi-Dell'Acqua, C., Tomasino, B., and Fink, G. R. (2009). What is the position of an arm relative to the body? Neural correlates of body schema and body structural description. J. Neurosci. 29, 4162-4171.

Coslett, H. B., and Lie, G. (2008). Simultanagnosia: when a rose is not red. J. Cogn. Neurosci. 20, 36-48.

Cotman, C. W. (1987). Excitatory amino acids in the brain-focus on NMDA receptors. Trends Neurosci. 10, 263-265.

Couture, S. M., Penn, D. L., Losh, M., Adolphs, R., Hurley, R., and Piven, J. (2010). Comparison of social cognitive functioning in schizophrenia and high functioning autism: more convergence than divergence. Psychol. Med. 40, 569-579.

Coyle, J. T. (1996). The glutamatergic dysfunction hypothesis for schizophrenia. Harv. Rev. Psychiatry 3, 241-253. 
Coyle, J. T. (2006). Glutamate and schizophrenia: beyond the dopamine hypothesis. Cell. Mol. Neurobiol. 26, 365-384.

Craig, A. D. (2009). How do you feel-now? The anterior insula and human awareness. Nat. Rev. Neurosci. 10, 59-70.

Cristinzio, C., N’Diaye, K., Seeck, M., Vuilleumier, P., and Sander, D. (2010). Integration of gaze direction and facial expression in patients with unilateral amygdala damage. Brain 133, 248-261.

Critchley, M. (1953). The Parietal Lobes. New York, NY: Hafner.

Cummings, J. L. (1997). Neuropsychiatric manifestations of right hemisphere lesions. Brain Lang. 57, 22-37.

Curtis, C. E., and D'Esposito, M. (2003). Persistent activity in the prefrontal cortex during working memory. Trends Cogn. Sci. 7, 415-423.

D'Esposito, M., and Postle, B. R. (1999). The dependence of span and delayed-response performance on prefrontal cortex. Neuropsychologia 37, 1303-1315.

David, N., Cohen, M. X., Newen, A., Bewernick, B. H., Shah, N. J., Fink, G. R., and Vogeley, K. (2007). The extrastriate cortex distinguishes between the consequences of one's own and others' behavior. Neuroimage 36, 1004-1014.

Decety, J., and Grezes, J. (1999). Neural mechanisms subserving the perception of human actions. Trends Cogn. Sci. 3, 172-178.

Decety, J., and Grezes, J. (2006). The power of simulation: imagining one's own and other's behavior. Brain Res. 1079, 4-14.

Decety, J., and Lamm, C. (2007). The role of the right temporoparietal junction in social interaction: how low-level computational processes contribute to metacognition. Neuroscientist 13, 580-593.

Decety, J., and Sommerville, J. A. (2003). Shared representations between self and other: a social cognitive neuroscience view. Trends Cogn. Sci. 7, 527-533.

Devinsky, O. (2008). Postictal psychosis: common, dangerous, and treatable. Epilepsy Curr. 8, 31-34.

Dimberg, U., Thunberg, M., and Elmehed, K. (2000). Unconscious facial reactions to emotional facial expressions. Psychol. Sci. 11, 86-89.

Ditman, T., and Kuperberg, G. R. (2010). Building coherence: a framework for exploring the breakdown of links across clause boundaries in schizophrenia. J. Neurolinguist. 23, 254-269.

Duff, M. C., Hengst, J. A., Tranel, D., and Cohen, N. J. (2009). Hippocampal amnesia disrupts verbal play and the creative use of language in social interaction. Aphasiology 23, 926-939.

Eliez, S., Blasey, C. M., Schmitt, E. J., White, C. D., Hu, D., and Reiss, A. L. (2001). Velocardiofacial syndrome: are structural changes in the temporal and mesial temporal regions related to schizophrenia? Am. J. Psychiatry 158, 447-453.

Elliott, B., Joyce, E., and Shorvon, S. (2009). Delusions, illusions and hallucinations in epilepsy: 2. Complex phenomena and psychosis. Epilepsy Res. 85, 172-186.

Elvevag, B., and Goldberg, T. E. (2000). Cognitive impairment in schizophrenia is the core of the disorder. Crit. Rev. Neurobiol. 14, $1-21$.

Emery, N. J. (2000). The eyes have it: the neuroethology, function and evolution of social gaze. Neurosci. Biobehav. Rev. 24, 581-604.

Ewbank, M. P., Jennings, C., and Calder, A. J. (2009). Why are you angry with me? Facial expressions of threat influence perception of gaze direction. J. Vis. 9, 16.1-16.7.

Farrer, C., Franck, N., Frith, C. D., Decety, J., Georgieff, N., D'Amato, T., and Jeannerod, M. (2004). Neural correlates of action attribution in schizophrenia. Psychiatry Res. 131, 31-44.

Farrer, C., and Frith, C. D. (2002), Experiencing oneself vs. another person as being the cause of an action: the neural correlates of the experience of agency. Neuroimage $15,596-603$.

Feinberg, T. E., Haber, L. D., and Leeds, N. E. (1990). Verbal asomatognosia. Neurology 40, 1391-1394.

Feinberg, T. E., Roane, D. M., and Ali, J. (2000). Illusory limb movements in anosognosia for hemiplegia. J. Neurol. Neurosurg. Psychiatry 68, 511-513.

Fellows, L. K., and Farah, M. J. (2005). Is anterior cingulate cortex necessary for cognitive control? Brain 128, 788-796.

Ffytche, D. H., Howard, R. J., Brammer M. J., David, A., Woodruff, P., and Williams, S. (1998). The anatomy of conscious vision: an fMRI study of visual hallucinations. Nat. Neurosci. $1,738-742$.

Fletcher, P. C., and Frith, C. D. (2009). Perceiving is believing: a Bayesian approach to explaining the positive symptoms of schizophrenia. Nat. Rev. Neurosci. 10 48-58.

Fogassi, L., Ferrari, P. F., Gesierich, B., Rozzi, S., Chersi, F., and Rizzolatti G. (2005). Parietal lobe: from action organization to intention understanding. Science 308 662-667.

Foxe, J. J., Doniger, G. M., and Javitt, D. C. (2001). Early visual processing deficits in schizophrenia: impaired P1 generation revealed by high-density electrical mapping. Neuroreport 12, 3815-3820.

Foxe, J. J., Wylie, G. R., Martinez, A., Schroeder, C. E., Javitt, D C., Guilfoyle, D., Ritter, W., and Murray, M. M. (2002). Auditorysomatosensory multisensory processing in auditory association cortex: an fMRI study. J. Neurophysiol. $88,540-543$.

Franck, N., O'Leary, D. S., Flaum, M. Hichwa, R. D., and Andreasen, N. C. (2002). Cerebral blood flow changes associated with Schneiderian firstrank symptoms in schizophrenia. J. Neuropsychiatry Clin. Neurosci. 14, 277-282.

Freeman, D., Garety, P. A., Kuipers, E., Fowler, D., and Bebbington, P. E. (2002). A cognitive model of persecutory delusions. Br. J. Clin. Psychol 41, 331-347.

Frisk, V., and Milner, B. (1990). The relationship of working memory to the immediate recall of stories following unilateral temporal or frontal lobectomy. Neuropsychologia 28, 121-135.

Frith, C. D., Friston, K. J., Liddle, P. F., and Frackowiak, R. S. (1992). PET imaging and cognition in schizophrenia. J. R. Soc. Med. 85, 222-224.

Fujii, N., Hihara, S., and Iriki, A. (2007). Dynamic social adaptation of motion-related neurons in primate parietal cortex. PLoS ONE 2:e397. doi: 10.1371/journal. pone.0000397

Garrity, A. G., Pearlson, G. D. McKiernan, K., Lloyd, D., Kiehl, K. A., and Calhoun, V. D. (2007) Aberrant "default mode" functional connectivity in schizophrenia. Am. J. Psychiatry 164 450-457.

Gauntlett-Gilbert, J., and Kuipers, E. (2003). Phenomenology of visual hallucinations in psychiatric conditions. J. Nerv. Ment. Dis. 191 203-205.

Gerstmann, J. (1942). Problem of imperception of disease and of impaired body territories with organic lesions. Arch. Neurol. Psychiatry 48, 890-913.
Geschwind, N. (1965). Disconnexion syndromes in animals and man. I. Brain 88, 237-294.

Ghazanfar, A. A., Chandrasekaran, C., and Logothetis, N. K. (2008) Interactions between the superior temporal sulcus and auditory cortex mediate dynamic face/voice integration in rhesus monkeys. J. Neurosci. 28, 4457-4469.

Ghent, L., Mishkin, M., and Teuber, H. L. (1962). Short-term memory after frontal-lobe injury in man. J. Comp. Physiol. Psychol. 55, 705-709.

Ghose, S., Chin, R., Gallegos, A., Roberts, R., Coyle, J., and Tamminga, C. (2009). Localization of NAAG-related gene expression deficits to the anterior hippocampus in schizophrenia. Schizophr. Res. 111, 131-137.

Gobbini, M. I., and Haxby, J. V. (2007). Neural systems for recognition of familiar faces. Neuropsychologia 45, 32-41.

Goldman-Rakic, P. (1991). "Prefrontal cortical dysfunction in schizophrenia: the relevance of working memory," in Psychopathology and the Brain, eds B. J. Carroll and J. E. Barrett (New York, NY: Raven Press), 1-23.

Goldman-Rakic, P. S. (1994). Working memory dysfunction in schizophrenia. J. Neuropsychiatry Clin. Neurosci. 6, 348-357.

Goldman-Rakic, P. S., Castner, S. A., Svensson, T. H., Siever, L. J., and Williams, G. V. (2004). Targeting the dopamine D1 receptor in schizophrenia: insights for cognitive dysfunction. Psychopharmacology (Berl.) 174, 3-16.

Gottlieb, J. (2007). From thought to action: the parietal cortex as a bridge between perception, action, and cognition. Neuron 53, 9-16.

Gould, E., Tanapat, P., Rydel, T., and Hastings, N. (2000). Regulation of hippocampal neurogenesis in adulthood. Biol. Psychiatry 48, 715-720.

Grezes, J., Pichon, S., and de Gelder, B. (2007). Perceiving fear in dynamic body expressions. Neuroimage 35, 959-967.

Grossman, E. D., Battelli, L., and Pascual-Leone, A. (2005). Repetitive TMS over posterior STS disrupts perception of biological motion Vision Res. 45, 2847-2853.

Grunze, H. C., Rainnie, D. G., Hasselmo, M. E., Barkai, E., Hearn, E. F., McCarley, R. W., and Greene, R. W. (1996). NMDAdependent modulation of CA1 local circuit inhibition. J. Neurosci. 16, 2034-2043.

Grüsser, O. J., Pause, M., and Schreiter, U. (1990). Localization and 
responses of neurones in the parieto-insular vestibular cortex of awake monkeys (Macaca fascicularis). J. Physiol. 430, 537-557.

Gur, R. E., Kohler, C. G., Ragland, J. D., Siegel, S. J., Lesko, K., Bilker, W. B., and Gur, R. C. (2006). Flat affect in schizophrenia: relation to emotion processing and neurocognitive measures. Schizophr. Bull. 32, 279-287.

Gur, R. E., Loughead, J., Kohler, C. G., Elliott, M. A., Lesko, K., Ruparel, K., Wolf, D. H., Bilker, W. B., and Gur, R. C. (2007). Limbic activation associated with misidentification of fearful faces and flat affect in schizophrenia. Arch. Gen. Psychiatry 64, 1356-1366.

Gur, R. E., Turetsky, B. I., Cowell, P. E., Finkelman, C., Maany, V., Grossman, R. I., Arnold, S. E., Bilker, W. B., and Gur, R. C. (2000). Temporolimbic volume reductions in schizophrenia. Arch. Gen. Psychiatry 57, 769-775.

Hall, J., Whalley, H. C., McKirdy, J. W., Romaniuk, L., McGonigle, D., McIntosh, A. M., Baig, B. J., Gountouna, V. E., Job, D. E., Donaldson, D. I., Sprengelmeyer, R., Young, A. W., Johnstone, E. C., and Lawrie, S. M. (2008). Overactivation of fear systems to neutral faces in schizophrenia. Biol. Psychiatry 64, 70-73.

Han, S. D., Nestor, P. G., Hale-Spencer, M., Cohen, A., Niznikiewicz, M., McCarley, R. W., and Wible, C. G. (2007). Functional neuroimaging of word priming in males with chronic schizophrenia. Neuroimage $35,273-282$.

Harrison, B. J., Yucel, M., Pujol, J., and Pantelis, C. (2007). Taskinduced deactivation of midline cortical regions in schizophrenia assessed with fMRI. Schizophr. Res. $91,82-86$.

Hart, J., and Gordon, B. (1990). Delineation of single-word semantic comprehension deficits in aphasia, with anatomical correlation. Ann. Neurol. 27, 226-231.

Hashimoto, R. I., Lee, K., Preus, A., McCarley, R. W., and Wible, C. G. (2010). An fMRI study of functional abnormalities in the verbal working memory system and the relationship to clinical symptoms in chronic schizophrenia. Cereb. Cortex 20, 46-60.

Heckers, S. (2001). Neuroimaging studies of the hippocampus in schizophrenia. Hippocampus 11, 520-528.

Heckers, S., and Konradi, C. (2010). Hippocampal pathology in schizophrenia. Curr. Top. Behav. Neurosci. 4, 529-553.

Heckers, S., Rauch, S. L., Goff, D., Savage, C. R., Schacter, D. L., Fischman, A. J., and Alpert, N. M. (1998). Impaired recruitment of the hippocampus during conscious recollection in schizophrenia. Nat. Neurosci. 1, 318-323.

Heckers, S., Stone, D., Walsh, J., Shick, J., Koul, P., and Benes, F. M. (2002). Differential hippocampal expression of glutamic acid decarboxylase 65 and 67 messenger RNA in bipolar disorder and schizophrenia. Arch. Gen. Psychiatry 59, 521-529.

Hein, G., and Knight, R. T. (2008). Superior temporal sulcus-It's my area: or is it? J. Cogn. Neurosci. 20, 2125-2136.

Heinks-Maldonado, T. H., Mathalon, D. H., Houde, J. F., Gray, M., Faustman, W. O., and Ford, J. M. (2007). Relationship of imprecise corollary discharge in schizophrenia to auditory hallucinations. Arch. Gen. Psychiatry 64, 286-296.

Hoffman, R. E. (2007). A social deafferentation hypothesis for induction of active schizophrenia. Schizophr. Bull. 33, 1066-1070.

Holt, D. J., Titone, D., Long, L. S., Goff, D. C., Cather, C., Rauch, S. L., Judge, A., and Kuperberg, G. R. (2006). The misattribution of salience in delusional patients with schizophrenia. Schizophr. Res. 83, 247-256.

Honea, R., Crow, T. J., Passingham, D., and Mackay, C. E. (2005). Regional deficits in brain volume in schizophrenia: a meta-analysis of voxel-based morphometry studies. Am. J. Psychiatry 162, 2233-2245.

Honea, R. A., Meyer-Lindenberg, A., Hobbs, K. B., Pezawas, L., Mattay, V. S., Egan, M. F., Verchinski, B., Passingham, R. E., Weinberger, D. R., and Callicott, J. H. (2008). Is gray matter volume an intermediate phenotype for schizophrenia? A voxel-based morphometry study of patients with schizophrenia and their healthy siblings. Biol. Psychiatry 63, 465-474.

Hooker, C., and Park, S. (2002). Emotion processing and its relationship to social functioning in schizophrenia patients. Psychiatry Res. 112, 41-50.

Hubl, D., Koenig, T., Strik, W., Federspiel, A., Kreis, R., Boesch, C., Maier, S. E., Schroth, G., Lovblad, K., and Dierks, T. (2004). Pathways that make voices: white matter changes in auditory hallucinations. Arch. Gen. Psychiatry 61, 658-668.
Hutchinson, J. B., Uncapher, M. R., and Wagner, A. D. (2009). Posterior parietal cortex and episodic retrieval: convergent and divergent effects of attention and memory. Learn. Mem. 16, 343-356.

Ishii, R., Canuet, L., Iwase, M. Kurimoto, R., Ikezawa, K., Robinson, S. E., Ukai, S., Shinosaki, K., Hirata, M., Yoshimine, T., and Takeda, M. (2006). Right parietal activation during delusional state in episodic interictal psychosis of epilepsy: a report of two cases. Epilepsy Behav. 9, 367-372.

Jardri, R., Lucas, B., Delevoye-Turrell Y., Delmaire, C., Delion, P., Thomas, P., and Goeb, J. L. (2007). An 11-year-old boy with drugresistant schizophrenia treated with temporo-parietal rTMS. Mol. Psychiatry 12, 320.

Javitt, D. C. (2007). Glutamate and schizophrenia: phencyclidine, $\mathrm{N}$ methyl-D-aspartate receptors, and dopamine-glutamate interactions. Int. Rev. Neurobiol. 78, 69-108.

Javitt, D. C. (2009). When doors of perception close: bottom-up models of disrupted cognition in schizophrenia. Annu. Rev. Clin. Psychol. 5, 249-275.

Jellema, T., Baker, C. I., Wicker, B. and Perrett, D. I. (2000). Neural representation for the perception of the intentionality of actions. Brain Cogn. 44, 280-302.

Jellema, T., Maassen, G., and Perrett, D. I. (2004). Single cell integration of animate form, motion and location in the superior temporal cortex of the macaque monkey. Cereb. Cortex 14, 781-790.

Jellema, T., and Perrett, D. I. (2003). Perceptual history influences neural responses to face and body postures. J. Cogn. Neurosci. 15, 961-971.

Jensen, J., Smith, A. J., Willeit, M., Crawley, A. P., Mikulis, D. J., Vitcu, I., and Kapur, S. (2007). Separate brain regions code for salience vs. valence during reward prediction in humans. Hum. Brain Mapp. 28, 294-302.

Kahn, I., Andrews-Hanna, J. R. Vincent, J. L., Snyder, A. Z., and Buckner, R. L. (2008). Distinct cortical anatomy linked to subregions of the medial temporal lobe revealed by intrinsic functional connectivity. J. Neurophysiol. 100 , 129-139.

Kapur, S. (2003). Psychosis as a state of aberrant salience: a framework linking biology, phenomenology, and pharmacology in schizophrenia. Am. J. Psychiatry 160, 13-23.

Karnath, H. O., Ferber, S., and Himmelbach, M. (2001). Spatial awareness is a function of the temporal not the posterior parietal lobe. Nature 411, 950-953.

Kasai, K., Shenton, M. E., Salisbury, D. F., Hirayasu, Y., Onitsuka, T., Spencer, M. H., Yurgelun-Todd, D. A., Kikinis, R., Jolesz, F. A., and McCarley, R. W. (2003). Progressive decrease of left Heschl gyrus and planum temporale gray matter volume in first-episode schizophrenia: a longitudinal magnetic resonance imaging study. Arch. Gen. Psychiatry 60, 766-775.

Kayser, C., Petkov, C. I., Augath, M., and Logothetis, N. K. (2005). Integration of touch and sound in auditory cortex. Neuron 48, 373-384.

Kerns, J. G., Nuechterlein, K. H., Braver, T. S., and Barch, D. M. (2008). Executive functioning component mechanisms and schizophrenia. Biol. Psychiatry 64, 26-33.

Keysers, C., and Gazzola, V. (2007). Integrating simulation and theory of mind: from self to social cognition. Trends Cogn. Sci. 11, 194-196.

Keysers, C., Wicker, B., Gazzola, V., Anton, J. L., Fogassi, L., and Gallese, V. (2004). A touching sight: SII/PV activation during the observation and experience of touch. Neuron 42, 335-346.

Klein, J. T., Deaner, R. O., and Platt, M. L. (2008). Neural correlates of social target value in macaque parietal cortex. Curr. Biol. 18, 419-424.

Kleinke, C. L. (1986). Gaze and eye contact: a research review. Psychol. Bull. 100, 78-100.

Kober, H., Barrett, L. F., Joseph, J., Bliss-Moreau, E., Lindquist, K., and Wager, T. D. (2008). Functional grouping and cortical-subcortical interactions in emotion: a metaanalysis of neuroimaging studies. Neuroimage 42, 998-1031.

Kohler, C. G., Turner, T. H., Bilker, W. B., Brensinger, C. M., Siegel, S. J., Kanes, S. J., Gur, R. E., and Gur, R. C. (2003). Facial emotion recognition in schizophrenia: intensity effects and error pattern. Am. J. Psychiatry 160, 1768-1774.

Kreifelts, B., Ethofer, T., Grodd, W., Erb, M., and Wildgruber, D. (2007). Audiovisual integration of emotional signals in voice and face: an event-related fMRI study. Neuroimage 37, 1445-1456.

Kring, A. M., Kerr, S. L., Smith, D. A., and Neale, J. M. (1993). Flat affect in schizophrenia does not reflect diminished subjective experience of emotion. J. Abnorm. Psychol. 102, 507-517. 
Kring, A. M., and Moran, E. K. (2008). Emotional response deficits in schizophrenia: insights from affective science. Schizophr. Bull. 34, 819-834.

Kubicki, M., McCarley, R. W., Nestor, P. G., Huh, T., Kikinis, R., Shenton, M. E., and Wible, C. G. (2003). An fMRI study of semantic processing in men with schizophrenia. Neuroimage 20, 1923-1933.

Kuperberg, G., and Heckers, S. (2000). Schizophrenia and cognitive function. Curr. Opin. Neurobiol. 10, 205-210.

Lee, S. H., Kim, W., Chung, Y. C., Jung, K. H., Bahk, W. M., Jun, T. Y., Kim, K. S., George, M. S., and Chae, J. H. (2005). A double blind study showing that two weeks of daily repetitive TMS over the left or right temporoparietal cortex reduces symptoms in patients with schizophrenia who are having treatment-refractory auditory hallucinations. Neurosci. Lett. 376, 177-81.

Leitman, D. I., Loughead, J., Wolf, D. H., Ruparel, K., Kohler, C. G., Elliott, M. A., Bilker, W. B., Gur, R. E., and Gur, R. C. (2008). Abnormal superior temporal connectivity during fear perception in schizophrenia. Schizophr. Bull. 34, 673-678.

Leitman, D. I., Wolf, D. H., Ragland, J. D., Laukka, P., Loughead, J., Valdez, J. N., Javitt, D. C., Turetsky, B. I., and Gur, R. C. (2010). "It's Not What You Say, But How You Say it": a reciprocal temporo-frontal network for affective prosody. Front. Hum. Neurosci. 4:19. doi: 10.3389/fnhum. 2010.00019

Lencz, T., Szeszko, P. R., Derosse, P., Burdick, K. E., Bromet, E. J., Bilder, R. M., and Malhotra, A. K. (2010). A schizophrenia risk gene, ZNF804A, influences neuroanatomical and neurocognitive phenotypes. Neuropsychopharmacology 35 , 2284-2291.

Lennox, B. R., Park, S. B., Jones, P. B., and Morris, P. G. (1999). Spatial and temporal mapping of neural activity associated with auditory hallucinations. Lancet 353, 644 .

Levine, D. N., and Finklestein, S. (1982). Delayed psychosis after right temporoparietal stroke or trauma: relation to epilepsy. Neurology 32, 267-273.

Lewis, D. A., Hashimoto, T., and Volk, D. W. (2005). Cortical inhibitory neurons and schizophrenia. Nat. Rev. Neurosci. 6, 312-324.

Lewis, J. W., and van Essen, D. C. (2000). Corticocortical connections of visual, sensorimotor, and multimodal processing areas in the parietal lobe of the macaque monkey. J. Comp. Neurol. 428, 112-137.

Li, K. X., Lu, Y. M., Xu, Z. H., Zhang, J., Zhu, J. M., Zhang, J. M. Cao, S. X., Chen, X. J., Chen, Z., Luo, J. H., Duan, S., and Li, X M. (2011). Neuregulin 1 regulates excitability of fast-spiking neurons through Kv1.1 and acts in epilepsy. Nat. Neurosci. 15, 267-273.

Lombardo, M. V., Chakrabarti, B., Bullmore, E. T., Wheelwright, S. J., Sadek, S. A., Suckling, J., and BaronCohen, S. (2010). Shared neural circuits for mentalizing about the self and others. J. Cogn. Neurosci. 22, 1623-1635.

Lotze, M., Heymans, U., Birbaumer, N., Veit, R., Erb, M., Flor, H., and Halsband, U. (2006). Differential cerebral activation during observation of expressive gestures and motor acts. Neuropsychologia 44, 1787-1795.

Luo, H., Liu, Z., and Poeppel, D. (2010). Auditory cortex tracks both auditory and visual stimulus dynamics using low-frequency neuronal phase modulation. PLoS Biol. 8:e1000445. doi: 10.1371/journal. pbio. 1000445

Macaluso, E. (2006). Multisensory processing in sensory-specific cortical areas. Neuroscientist 12 327-338.

Macaluso, E., Frith, C. D., and Driver, J. (2000). Modulation of human visual cortex by crossmodal spatial attention. Science 289, 1206-1208.

Maher, B. A. (1974). Delusional thinking and perceptual disorder. $J$. Individ. Psychol. 30, 98-113.

Manchanda, R., Miller, H., and McLachlan, R. S. (1993). Post-ictal psychosis after right temporal lobectomy. J. Neurol. Neurosurg. Psychiatry 56, 277-279.

Manoach, D. S. (2003). Prefrontal cortex dysfunction during working memory performance in schizophrenia: reconciling discrepant findings. Schizophr. Res. 60, 285-298.

Manoach, D. S., Greve, D. N., Lindgren, K. A., and Dale, A. M. (2003). Identifying regional activity associated with temporally separated components of working memory using event-related functional MRI. Neuroimage 20, 1670-1684.

Manoach, D. S., Ketwaroo, G. A., Polli, F. E., Thakkar, K. N., Barton, J. J., Goff, D. C., Fischl, B., Vangel, M., and Tuch, D. S. (2007). Reduced microstructural integrity of the white matter underlying anterior cingulate cortex is associated with increased saccadic latency in schizophrenia. Neuroimage 37, 599-610.

Manoach, D. S., Lindgren, K. A., Cherkasova, M. V., Goff, D. C. Halpern, E. F., Intriligator, J., and Barton, J. J. (2002). Schizophrenic subjects show deficient inhibition but intact task switching on saccadic tasks. Biol. Psychiatry 51, 816-826.

Marian, G., Nica, E. A., Ionescu, B. E., and Ghinea, D. (2009). Hyperthyroidism-cause of depression and psychosis: a case report. J. Med. Life $2,440-442$.

Martinez, A., Ramanathan, D. S., Foxe, J. J., Javitt, D. C., and Hillyard, S. A (2007). The role of spatial attention in the selection of real and illusory objects. J. Neurosci. 27, 7963-7973.

Mathews, J. R., and Barch, D. M. (2010). Emotion responsivity, social cognition, and functional outcome in schizophrenia. J. Abnorm. Psychol. 119, 50-59.

Matsuhashi, M., Ikeda, A., Ohara S., Matsumoto, R., Yamamoto, J. Takayama, M., Satow, T., Begum, T., Usui, K., Nagamine, T., Mikuni, N., Takahashi, J., Miyamoto, S. Fukuyama, H., and Shibasaki, H. (2004). Multisensory convergence at human temporo-parietal junction-epicortical recording of evoked responses. Clin. Neurophysiol. 115, 1145-1160.

McCarthy, G. (2010). Faces, Agents, and Animacy: Neurophysiological Studies of Social Perception. (Talk given at BCS MIT on Friday March 19, 2010).

McGhie, A., and Chapman, J. (1961) Disorders of attention and perception in early schizophrenia. $\mathrm{Br}$. J. Med. Psychol. 34, 103-116.

Meyer, K. D., and Morris, J. A (2009). Discl regulates granule cell migration in the developing hippocampus. Hum. Mol. Genet. 18 , 3286-3297.

Miller, B. L., Cummings, J. L., McIntyre, H., Ebers, G., and Grode, M. (1986). Hypersexuality or altered sexual preference following brain injury. J. Neurol. Neurosurg. Psychiatry 49, 867-873.

Milner, A. D., and Goodale, M A. (2008). Two visual systems re-viewed. Neuropsychologia 46, 774-785.

Morris, J. P., Pelphrey, K. A., and McCarthy, G. (2008). Perceived causality influences brain activity evoked by biological motion. Soc. Neurosci. 3, 16-25.
Myin-Germeys, I., Delespaul, P. A., and Devries, M. W. (2000). Schizophrenia patients are more emotionally active than is assumed based on their behavior. Schizophr. Bull. 26, 847-854.

Narumoto, J., Okada, T., Sadato, N., Fukui, K., and Yonekura, Y. (2001). Attention to emotion modulates fMRI activity in human right superior temporal sulcus. Brain Res. Cogn. Brain Res. 12, 225-231.

Nicole, L., Lesage, A., and Lalonde, P. (1992). Lower incidence and increased male:female ratio in schizophrenia. Br. J. Psychiatry 161, 556-557.

Nielsen, J. M. (1946). Etiology of idiopathic epilepsy. Bull. Los Angel. Neuro. Soc. 11, 97-101.

Nummenmaa, L., and Calder, A. J. (2009). Neural mechanisms of social attention. Trends Cogn. Sci. 13, 135-143.

Nummenmaa, L., Passamonti, L., Rowe, J., Engell, A. D., and Calder, A. J. (2010). Connectivity analysis reveals a cortical network for eye gaze perception. Cereb. Cortex 20, 1780-1787.

Ochsner, K. N. (2008). The socialemotional processing stream: five core constructs and their translational potential for schizophrenia and beyond. Biol. Psychiatry 64 48-61.

Olney, J. W., and Farber, N. B. (1995). NMDA antagonists as neurotherapeutic drugs, psychotogens, neurotoxins, and research tools for studying schizophrenia. Neuropsychopharmacology 13 , 335-345.

Olney, J. W., Newcomer, J. W., and Farber, N. B. (1999). NMDA receptor hypofunction model of schizophrenia. J. Psychiatr. Res. 33, 523-533.

Oram, M. W., and Perrett, D. I. (1994) Responses of anterior superior temporal polysensory (STPa) neurons to "biological motion" stimuli. $J$ Cogn. Neurosci. 6, 99-116.

Oram, M. W., and Perrett, D. I. (1996) Integration of form and motion in the anterior superior temporal polysensory area (STPa) of the macaque monkey. J. Neurophysiol. 76, 109-129.

Padberg, J., Seltzer, B., and Cusick, C. G. (2003). Architectonics and cortical connections of the upper bank of the superior temporal sulcus in the rhesus monkey: an analysis in the tangential plane. J. Comp. Neurol. 467, 418-434

Pakalnis, A., Drake, M. E. Jr., an Kellum, J. B. (1987). Right parietooccipital lacunar infarction with 
agitation, hallucinations, and delusions. Psychosomatics 28, 95-96.

Pavlova, M., Lutzenberger, W., Sokolov, A., and Birbaumer, N. (2004). Dissociable cortical processing of recognizable and non-recognizable biological movement: analysing gamma MEG activity. Cereb. Cortex 14, 181-188.

Pelphrey, K. A., Morris, J. P., Michelich, C. R., Allison, T., and McCarthy, G. (2005). Functional anatomy of biological motion perception in posterior temporal cortex: an FMRI study of eye, mouth and hand movements. Cereb. Cortex 15, 1866-1876.

Pelphrey, K. A., Viola, R. J., and McCarthy, G. (2004). When strangers pass: processing of mutual and averted social gaze in the superior temporal sulcus. Psychol. Sci. 15, 598-603.

Penfield, W., and Perot, P. (1963). The brain's record of auditory and visual experience. A final summary and discussion. Brain 86, 595-696.

Peroutka, S. J., Sohmer, B. H., Kumar, A. J., Folstein, M., and Robinson, R. G. (1982). Hallucinations and delusions following a right temporoparietooccipital infarction. Johns Hopkins Med. J. 151, 181-185.

Perrett, D. I., Hietanen, J. K., Oram, M. W., and Benson, P. J. (1992). Organization and functions of cells responsive to faces in the temporal cortex. Philos. Trans. R. Soc. Lond. B Biol. Sci. 335, 23-30.

Perrett, D. I., Smith, P. A., Mistlin, A. J., Chitty, A. J., Head, A. S., Potter, D. D., Broennimann, R., Milner, A. D., and Jeeves, M. A. (1985a). Visual analysis of body movements by neurones in the temporal cortex of the macaque monkey: a preliminary report. Behav. Brain Res. 16, 153-170.

Perrett, D. I., Smith, P. A., Potter, D. D., Mistlin, A. J., Head, A. S., Milner, A. D., and Jeeves, M. A. (1985b). Visual cells in the temporal cortex sensitive to face view and gaze direction. Proc. R. Soc. Lond. B Biol. Sci. 223, 293-317.

Perrett, D. I., Xiao, D., Barraclough, N. E., Keysers, C., and Oram, M. W. (2009). Seeing the future: natural image sequences produce "anticipatory" neuronal activity and bias perceptual report. Q. J. Exp. Psychol. (Hove) 62, 2081-2104.

Petkova, V. I., and Ehrsson, H. H. (2008). If I were you: perceptual illusion of body swapping. PLoS
ONE 3:e3832. doi: 10.1371/journal.pone.0003832

Petrides, M., Alivisatos, B., Evans, A. C., and Meyer, E. (1993). Dissociation of human mid-dorsolateral from posterior dorsolateral frontal cortex in memory processing. Proc. Natl. Acad. Sci. U.S.A. 90, 873-877.

Phelps, E. A., and Anderson, A. K. (1997). Emotional memory: what does the amygdala do? Curr. Biol. 7 , R311-R314.

Pickup, G. J., and Frith, C. D. (2001). Theory of mind impairments in schizophrenia: symptomatology, severity and specificity. Psychol. Med. 31, 207-220.

Pinsk, M. A., Arcaro, M., Weiner, K. S., Kalkus, J. F., Inati, S. J., Gross, C. G., and Kastner, S. (2009). Neural representations of faces and body parts in macaque and human cortex: a comparative FMRI study. J. Neurophysiol. 101, 2581-2600.

Polli, F. E., Barton, J. J., Thakkar, K. N., Greve, D. N., Goff, D. C., Rauch, S. L., and Manoach, D. S. (2008). Reduced error-related activation in two anterior cingulate circuits is related to impaired performance in schizophrenia. Brain 131, 971-986.

Postle, B. R. (2006). Working memory as an emergent property of the mind and brain. Neuroscience 139, 23-38.

Powell, S. B., Sejnowski, T. J., and Behrens, M. M. (2012). Behavioral and neurochemical consequences of cortical oxidative stress on parvalbumininterneuron maturation in rodent models of schizophrenia. Neuropharmacology 62, 1322-1331.

Puce, A., and Perrett, D. (2003). Electrophysiology and brain imaging of biological motion. Philos Trans. R. Soc. Lond. B Biol. Sci. 358, 435-445.

Rabins, P. V., Starkstein, S. E., and Robinson, R. G. (1991). Risk factors for developing atypical (schizophreniform) psychosis following stroke. J. Neuropsychiatry Clin. Neurosci. 3, 6-9.

Ragland, J. D., Gur, R. C., Valdez, J. N., Loughead, J., Elliott, M. Kohler, C., Kanes, S., Siegel, S. J., Moelter, S. T., and Gur, R. E. (2005). Levels-of-processing effect on frontotemporal function in schizophrenia during word encoding and recognition. Am. J. Psychiatry 162, 1840-1848.

Redcay, E. (2008). The superior temporal sulcus performs a common function for social and speech perception: implications for the emergence of autism. Neurosci. Biobehav. Rev. 32, 123-142.

Redcay, E., Dodell-Feder, D., Pearrow, M. J., Mavros, P. L., Kleiner, M. Gabrieli, J. D., and Saxe, R. (2010). Live face-to-face interaction during fMRI: a new tool for social cognitive neuroscience. Neuroimage 50, 1639-1647.

Richardson, E. D., Malloy, P. F., and Grace, J. (1991). Othello syndrome secondary to right cerebrovascular infarction. J. Geriatr. Psychiatry Neurol. 4, 160-165.

Rilling, J. K., Winslow, J. T., and Kilts, C. D. (2004). The neural correlates of mate competition in dominant male rhesus macaques. Biol. Psychiatry 56, 364-375.

Rockland, K. S., and van Hoesen, G. W. (1999). Some temporal and parietal cortical connections converge in $\mathrm{CAl}$ of the primate hippocampus. Cereb. Cortex 9, 232-237.

Roiser, J. P., Stephan, K. E., Den Ouden, H. E., Barnes, T. R., Friston, K. J., and Joyce, E. M. (2009). Do patients with schizophrenia exhibit aberrant salience? Psychol. Med. 39, 199-209.

Rujescu, D., Bender, A., Keck, M., Hartmann, A. M., Ohl, F. Raeder, H., Giegling, I., Genius, J., McCarley, R. W., Moller, H. J., and Grunze, H. (2006). A pharmacological model for psychosis based on N-methyl-D-aspartate receptor hypofunction: molecular, cellular, functional and behavioral abnormalities. Biol. Psychiatry 59, 721-729.

Russell, T. A., Reynaud, E., KucharskaPietura, K., Ecker, C., Benson, P. J., Zelaya, F., Giampietro, V., Brammer, M., David, A., and Phillips, M. L. (2007). Neural responses to dynamic expressions of fear in schizophrenia. Neuropsychologia 45 107-123.

Samson, D., Apperly, I. A., Chiavarino, C., and Humphreys, G. W. (2004). Left temporoparietal junction is necessary for representing someone else's belief. Nat. Neurosci. 7, 499-500.

Santhouse, A. M., Howard, R. J., and Ffytche, D. H. (2000). Visual hallucinatory syndromes and the anatomy of the visual brain. Brain 123(Pt 10), 2055-2064.

Sapolsky, R. M. (1994). Glucocorticoids, stress and exacerbation of excitotoxic neuron death. Semin. Neurosci. 6, 323-331.

Sarfati, Y., Hardy-Bayle, M. C., Besche, C., and Widlocher, D. (1997) Attribution of intentions to others in people with schizophrenia: a non-verbal exploration with comic strips. Schizophr. Res. 25, 199-209.

Sarfati, Y., Hardy-Bayle, M. C., Brunet, E., and Widlocher, D. (1999). Investigating theory of mind in schizophrenia: influence of verbalization in disorganized and non-disorganized patients. Schizophr. Res. 37, 183-190.

Satterthwaite, T. D., Wolf, D. H., Loughead, J., Ruparel, K., Valdez, J. N., Siegel, S. J., Kohler, C. G., Gur, R. E., and Gur, R. C. (2010). Association of enhanced limbic response to threat with decreased cortical facial recognition memory response in schizophrenia. Am. J. Psychiatry 167, 418-426.

Saxe, R., and Wexler, A. (2005). Making sense of another mind: the role of the right temporo-parietal junction. Neuropsychologia 43, 1391-1399.

Saxe, R., Xiao, D. K., Kovacs, G., Perrett, D. I., and Kanwisher, N. (2004). A region of right posterior superior temporal sulcus responds to observed intentional actions Neuropsychologia 42, 1435-1446.

Schlee, W., Mueller, N., Hartmann, T., Keil, J., Lorenz, I., and Weisz, N. (2009). Mapping cortical hubs in tinnitus. BMC Biol. 7, 80

Schneider, G. E. (1969). Two visual systems. Science 163, 895-902.

Schobel, S. A., Lewandowski, N. M., Corcoran, C. M., Moore, H. Brown, T., Malaspina, D., and Small, S. A. (2009). Differential targeting of the CAl subfield of the hippocampal formation by schizophrenia and related psychotic disorders. Arch. Gen. Psychiatry 66, 938-946.

Scholz, J., Triantafyllou, C., WhitfieldGabrieli, S., Brown, E. N., and Saxe, R. (2009). Distinct regions of right temporo-parietal junction are selective for theory of mind and exogenous attention. PLOS ONE 4:e4869. doi: 10.1371/journal.pone. 0004869

Schultz, J., Imamizu, H., Kawato, M., and Frith, C. D. (2004). Activation of the human superior temporal gyrus during observation of goal attribution by intentional objects. J. Cogn. Neurosci. 16, 1695-1705.

Schulz, K., and Korz, V. (2010). Hippocampal testosterone relates to reference memory performance and synaptic plasticity in male rats. Front. Behav. Neurosci. 4:187. doi 10.3389/fnbeh.2010.00187

Segall, J. M., Turner, J. A., van Erp, T. G., White, T., Bockholt, H. J., 
Gollub, R. L., Ho, B. C., Magnotta, V., Jung, R. E., McCarley, R. W., Schulz, S. C., Lauriello, J., Clark, V. P., Voyvodic, J. T., Diaz, M. T., and Calhoun, V. D. (2009). Voxelbased morphometric multisite collaborative study on schizophrenia. Schizophr. Bull. 35, 82-95.

Seidman, L. J., Pantelis, C., Keshavan, M. S., Faraone, S. V., Goldstein, J. M., Horton, N. J., Makris, N., Falkai, P., Caviness, V. S., and Tsuang, M. T. (2003). A review and new report of medial temporal lobe dysfunction as a vulnerability indicator for schizophrenia: a magnetic resonance imaging morphometric family study of the parahippocampal gyrus. Schizophr. Bull. 29, 803-830.

Seltzer, B., and Pandya, D. N. (1978). Afferent cortical connections and architectonics of the superior temporal sulcus and surrounding cortex in the rhesus monkey. Brain Res. $149,1-24$.

Seltzer, B., and Pandya, D. N. (1994). Parietal, temporal, and occipital projections to cortex of the superior temporal sulcus in the rhesus monkey: a retrograde tracer study. J. Comp. Neurol. 343, 445-463.

Shenton, M. E., Dickey, C. C., Frumin, M., and McCarley, R. W. (2001). A review of MRI findings in schizophrenia. Schizophr. Res. 49, $1-52$.

Shepherd, S. V., Klein, J. T., Deaner, R. O., and Platt, M. L. (2009). Mirroring of attention by neurons in macaque parietal cortex. Proc. Natl. Acad. Sci. U.S.A. 106, 9489-9494.

Silbersweig, D., and Stern, E. (1996). Functional neuroimaging of hallucinations in schizophrenia: toward an integration of bottom-up and topdown approaches. Mol. Psychiatry 1 , 367-375.

Spence, S. A., Brooks, D. J., Hirsch, S. R., Liddle, P. F., Meehan, J., and Grasby, P. M. (1997). A PET study of voluntary movement in schizophrenic patients experiencing passivity phenomena (delusions of alien control). Brain 120(Pt 11), 1997-2011.

Startup, M., and Startup, S. (2005). On two kinds of delusion of reference. Psychiatry Res. 137, 87-92.

Swisher, J. D., Halko, M. A., Merabet, L. B., McMains, S. A., and Somers, D. C. (2007). Visual topography of human intraparietal sulcus. $J$. Neurosci. 27, 5326-5337.

Takahashi, H., Matsuura, M., Yahata, N., Koeda, M., Suhara, T., and
Okubo, Y. (2006). Men and women show distinct brain activations during imagery of sexual and emotional infidelity. Neuroimage 32, 1299-1307.

Tamminga, C. A., Lahti, A. C., Medoff, D. R., Gao, X. M., and Holcomb, H. H. (2003). Evaluating glutamatergic transmission in schizophrenia. Ann. N.Y. Acad. Sci. 1003 113-118.

Tan, H. Y., Callicott, J. H., and Weinberger, D. R. (2007). Dysfunctional and compensatory prefrontal cortical systems, genes and the pathogenesis of schizophrenia. Cereb. Cortex 17(Suppl. 1), i171-i181.

Thompson, K. G., and Bichot, N. P. (2005). A visual salience map in the primate frontal eye field. Prog. Brain Res. 147, 251-262.

Torrey, E. F. (2007). Schizophrenia and the inferior parietal lobule. Schizophr. Res. 97, 215-225.

Tsakiris, M. (2010). My body in the brain: a neurocognitive model of body-ownership. Neuropsychologia 48, 703-712.

Tseng, K. Y., Lewis, B. L., Lipska, B. K., and O'Donnell, P. (2007). Post-pubertal disruption of medial prefrontal cortical dopamineglutamate interactions in a developmental animal model of schizophrenia. Biol. Psychiatry $1 ; 62,730-8$

Tu, P., Buckner, R. L., Zollei, L., Dyckman, K. A., Goff, D. C., and Manoach, D. S. (2010). Reduced functional connectivity in a right-hemisphere network for volitional ocular motor control in schizophrenia. Brain 133, 625-637.

Uddin, L. Q., Molnar-Szakacs, I., Zaidel, E., and Iacoboni, M. (2006). rTMS to the right inferior parietal lobule disrupts self-other discrimination. Soc. Cogn. Affect. Neurosci. $1,65-71$.

Vallar, G., and Ronchi, R. (2009). Somatoparaphrenia: a body delusion. A review of the neuropsychological literature. Exp. Brain Res. 192, 533-551.

Vincent, J. L., Snyder, A. Z., Fox, M. D., Shannon, B. J., Andrews, J. R., Raichle, M. E., and Buckner, R. L. (2006). Coherent spontaneous activity identifies a hippocampal-parietal memory network. J. Neurophysiol. 96, 3517-3531.

Vohs, J. L., Hetrick, W. P., Kieffaber, P. D., Bodkins, M., Bismark, A., Shekhar, A., and O'Donnell, B. F. (2008). Visual event-related potentials in schizotypal personality disorder and schizophrenia. J. Abnorm. Psychol. 117, 119-131.

Wallbott, H. G. (1991). Recognition of emotion from facial expression via imitation? Some indirect evidence for an old theory. Br. J. Soc. Psychol. 30(Pt 3), 207-219.

Walter, H., Heckers, S., Kassubek, J. Erk, S., Frasch, K., and Abler, B. (2010). Further evidence for aberrant prefrontal salience coding in schizophrenia. Front. Behav. Neurosci. 3:62. doi: 10.3389/neuro 08.062.2009

Ward, I. L. (1984). The prenatal stress syndrome: current status. Psychoneuroendocrinology 9, 3-11.

Ward, I. L., and Reed, J. (1985). Prenatal stress and prepuberal social rearing conditions interact to determine sexual behavior in male rats. Behav. Neurosci. 99, 301-309.

Wheaton, K. J., Pipingas, A., Silberstein, R. B., and Puce, A. (2001). Human neural responses elicited to observing the actions of others. Vis. Neurosci. 18, 401-406.

Wheaton, K. J., Thompson, J. C., Syngeniotis, A., Abbott, D. F., and Puce, A. (2004). Viewing the motion of human body parts activates different regions of premotor, temporal, and parietal cortex. Neuroimage 22, 277-288.

Whitfield-Gabrieli, S., Thermenos, $\mathrm{H}$ W., Milanovic, S., Tsuang, M. T., Faraone, S. V., McCarley, R. W. Shenton, M. E., Green, A. I., NietoCastanon, A., Laviolette, P., Wojcik, J., Gabrieli, J. D., and Seidman, L. J. (2009). Hyperactivity and hyperconnectivity of the default network in schizophrenia and in first-degree relatives of persons with schizophrenia. Proc. Natl. Acad. Sci. U.S.A. 106 1279-1284.

Whitford, T. J., Ford, J. M., Mathalon, D. H., Kubicki, M., and Shenton, M. E. (2012). Schizophrenia, myelination, and delayed corollary discharges: a hypothesis. Schizophr Bull. 38, 486-494.

Wible, C. G. (2012). Schizophrenia as a disorder of social communication. Schizophr. Res. Treat. doi 10.1155/2012/920485. Article ID 920485, [Epub ahead of print].

Wible, C. G., Lee, K., Molina, I., Hashimoto, R., Preus, A. P., Roach, B. J., Ford, J. M., Mathalon, D H., McCarthey, G., Turner, J. A. Potkin, S. G., O'Leary, D., Belger, A., Diaz, M., Voyvodic, J., Brown, G. G., Notestine, R., Greve, D. and Lauriello, J. (2009a). fMRI Activity correlated with auditory hallucinations during performance of a working memory task: data from the FBIRN consortium study. Schizophr. Bull. 35, 47-57.

Wible, C. G., Preus, A. P., and Hashimoto, R. (2009b). A cognitive neuroscience view of schizophrenic symptoms: abnormal activation of a system for social perception and communication. Brain Imaging Behav. 3, 85-110.

Wible, C. G., Shenton, M. E. and McCarley, R. W. (1997). "Functional neuroanatomy of the limbic system and planum temporale," in Brain Imaging in Clinical Psychiatry, eds R. R. Krishnan and P. M. Doraiswamy (New York, NY: Marcel Dekker), 63-101.

Wildgruber, D., Riecker, A., Hertrich, I., Erb, M., Grodd, W., Ethofer T., and Ackermann, H. (2005). Identification of emotional intonation evaluated by fMRI. Neuroimage 24, 1233-1241.

Williams, L. E., Must, A., Avery, S., Woolard, A., Woodward, N. D., Cohen, N. J., and Heckers, S (2010). Eye-movement behavior reveals relational memory impairment in schizophrenia. Biol. Psychiatry 68, 617-624.

Williams, L. M., Whitford, T. J., Gordon, E., Gomes, L., Brown, K. J., and Harris, A. W. (2009). Neural synchony in patients with a first episode of schizophrenia: tracking relations with grey matter and symptom profile. J. Psychiatry Neurosci. 34, 21-29.

Woo, T. U., Shrestha, K., Lamb, D., Minns, M. M., and Benes, F. M. (2008). N-methyl-D-aspartate receptor and calbindin-containing neurons in the anterior cingulate cortex in schizophrenia and bipoar disorder. Biol. Psychiatry 64, 803-809.

Woo, T. U., Spencer, K., and McCarley, R. W. (2010). Gamma oscillation deficits and the onset and early progression of schizophrenia. Harv. Rev. Psychiatry 18 173-189.

Wright, T. M., Pelphrey, K. A., Allison, T., McKeown, M. J., and McCarthy, G. (2003). Polysensory interactions along lateral temporal regions evoked by audiovisual speech. Cereb. Cortex 13, 1034-1043.

Xu, J., Kemeny, S., Park, G., Frattali, C., and Braun, A. (2005). Language in context: emergent features of word, sentence, and narrative comprehension. Neuroimage 25, 1002-1015.

Young, L., Dodell-Feder, D., and Saxe, R. (2010). What gets the attention of the temporo-parietal junction? An fMRI investigation of attention and 
theory of mind. Neuropsychologia 48, 2658-2664.

Zhou, Y., Liang, M., Tian, L., Wang, K., Hao, Y., Liu, H., Liu, Z., and Jiang, T. (2007). Functional disintegration in paranoid schizophrenia using resting-state fMRI. Schizophr. Res. 97, 194-205.

Zola-Morgan, S., Squire, L. R., and Amaral, D. G. (1986). Human amnesia and the medial temporal region: enduring memory impairment following a bilateral lesion limited to field CA1 of the hippocampus. J. Neurosci. 6, 2950-2967.

Conflict of Interest Statement: The author declares that the research was conducted in the absence of any commercial or financial relationships that could be construed as a potential conflict of interest.

Received: 27 April 2011; accepted: 01 June 2012; published online: 22 June 2012.

Citation: Wible CG (2012) Hippocampal temporal-parietal junction interaction in the production of psychotic symptoms: a framework for understanding the schizophrenic syndrome. Front. Hum Neurosci. 6:180. doi: 10.3389/fnhum. 2012.00180

Copyright (c) 2012 Wible. This is an open-access article distributed under the terms of the Creative Commons Attribution Non Commercial License, which permits non-commercial use, distribution, and reproduction in other forums, provided the original authors and source are credited. 